\title{
An Efficient Synthesis of Nitroalkenes by Alkene Cross Metathesis: Facile Access to Small Ring Systems
}

Graham P. Marsh, Philip J. Parsons, ${ }^{*}$ Clive McCarthy, and Xavier G. Corniquet

Department of Chemistry, School of Life Sciences, University of Sussex, Falmer, Brighton, BN1 9QJ, UK, and Novartis Institutes for

Biomedical Research, Lichtstrasse 35, CH-4056 Basel, $\mathrm{CH}$.

p.j.parsons@sussex.ac.uk 


$$
\mathrm{O}_{2} \mathrm{~N} \overbrace{1}^{\curvearrowright}
$$

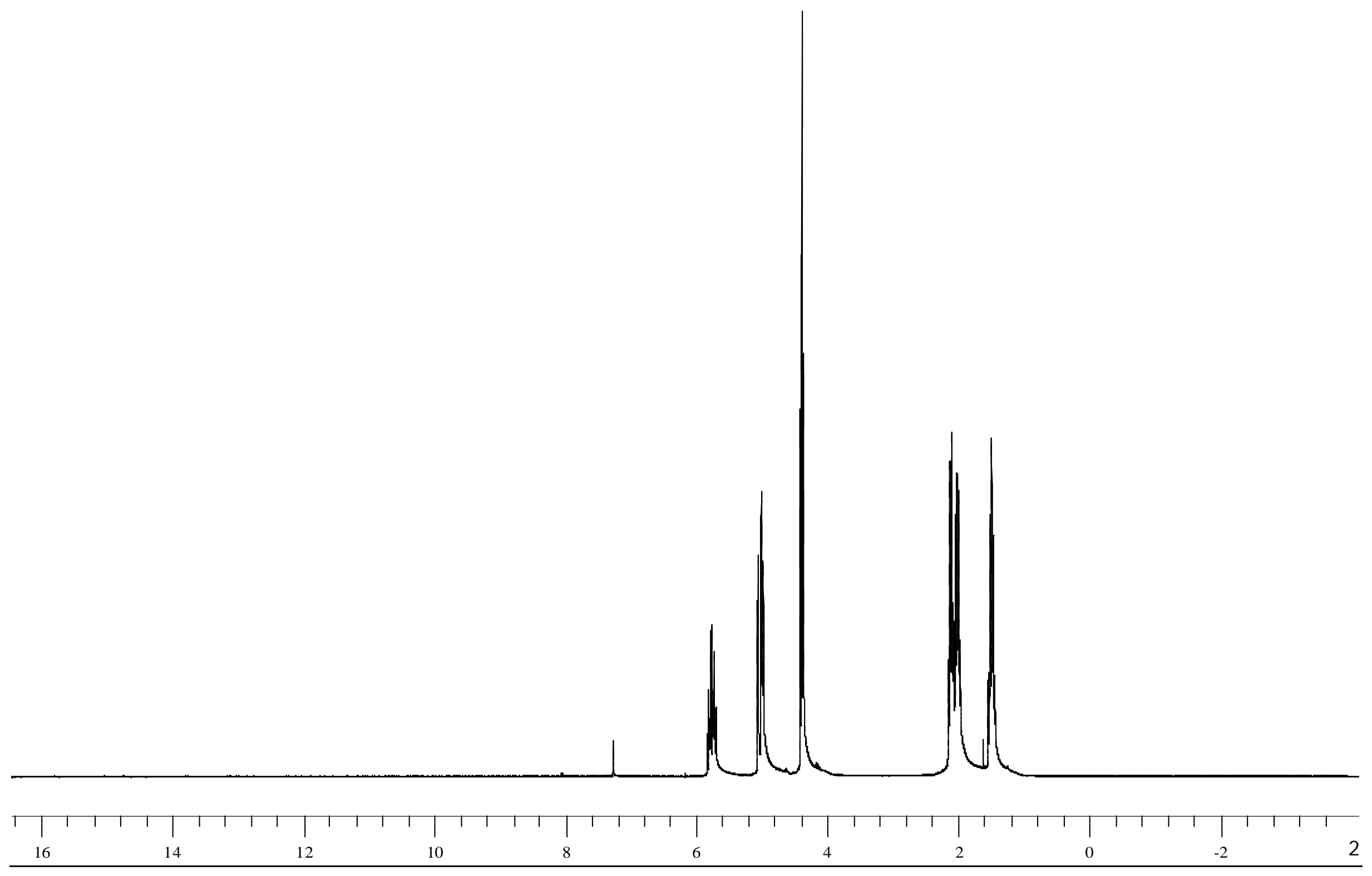




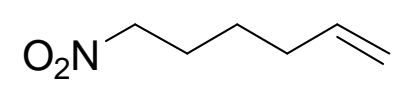

1

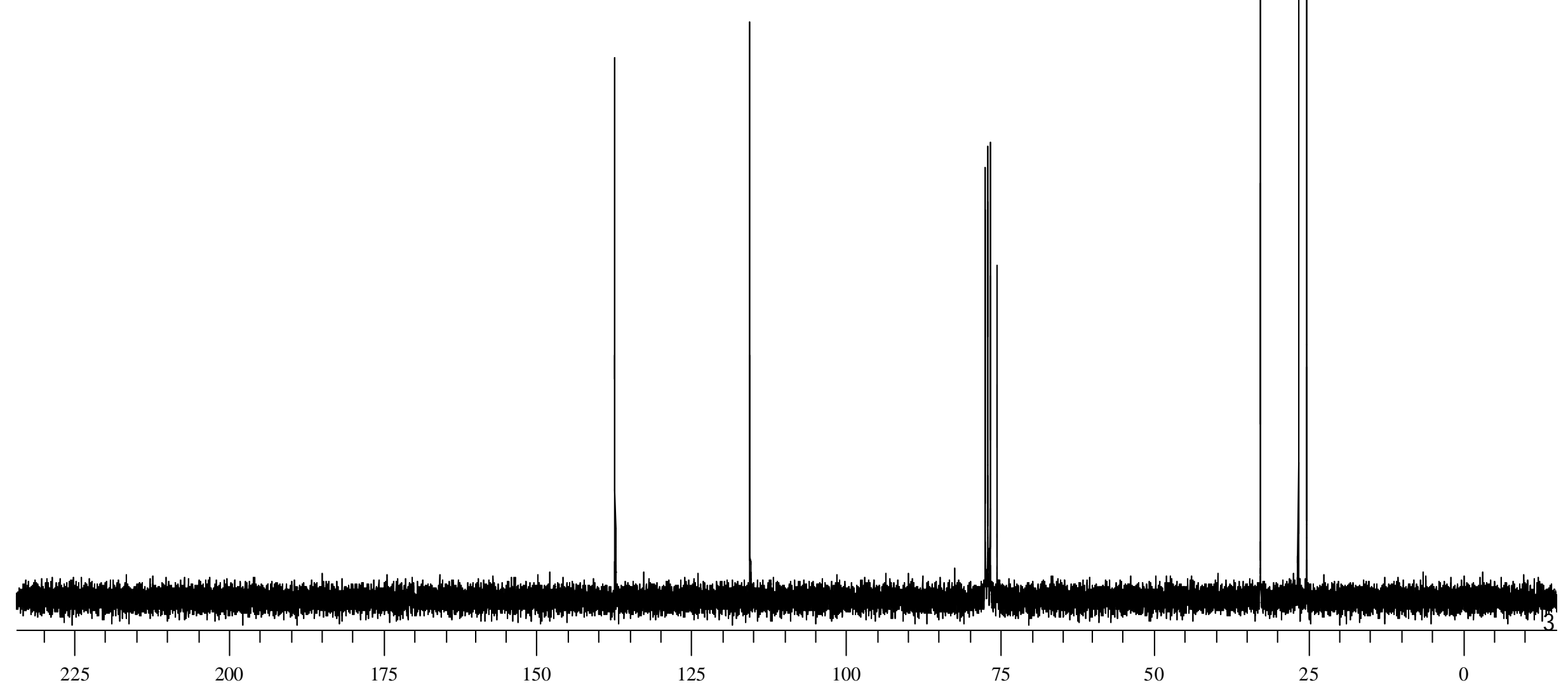




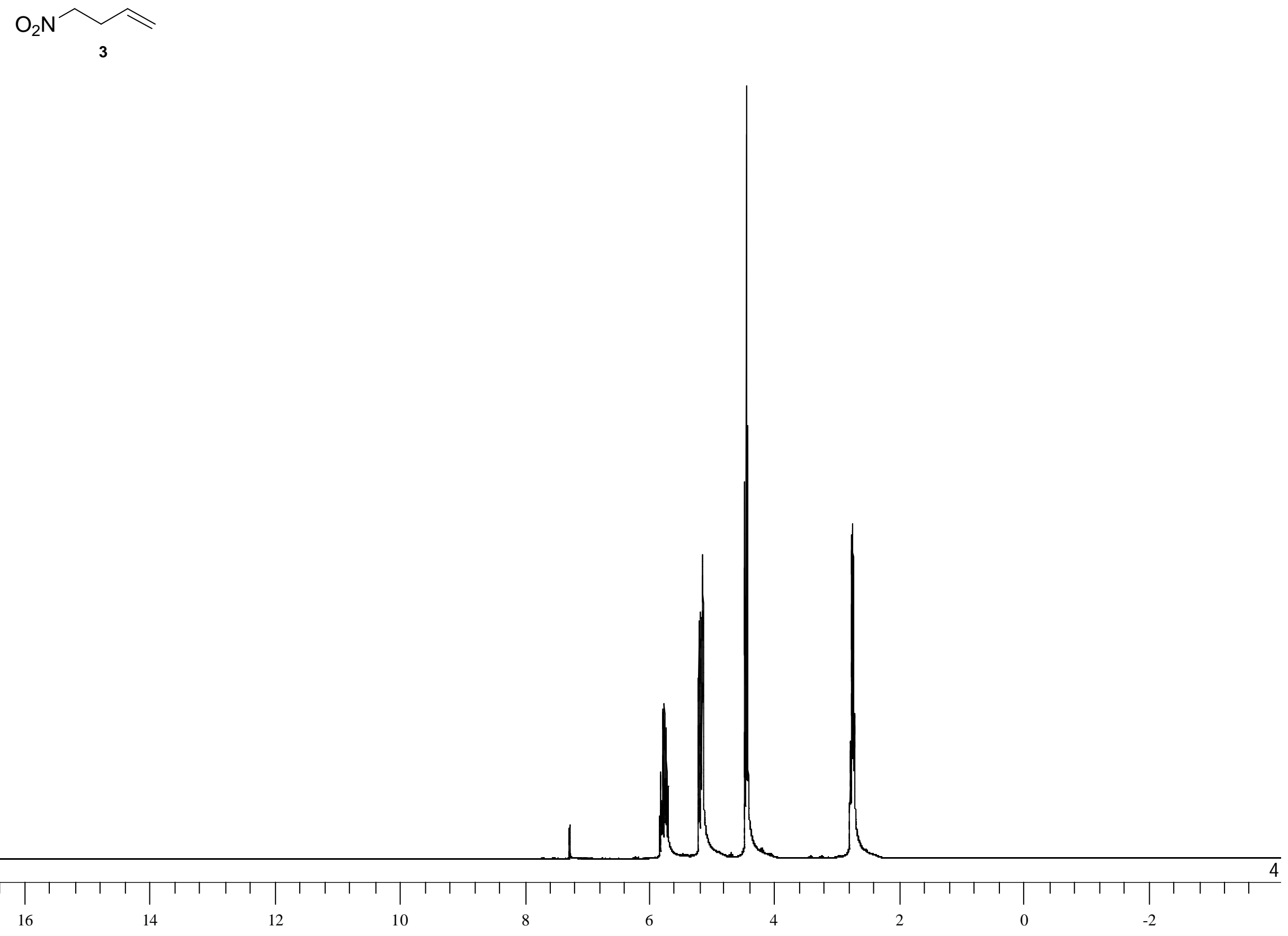



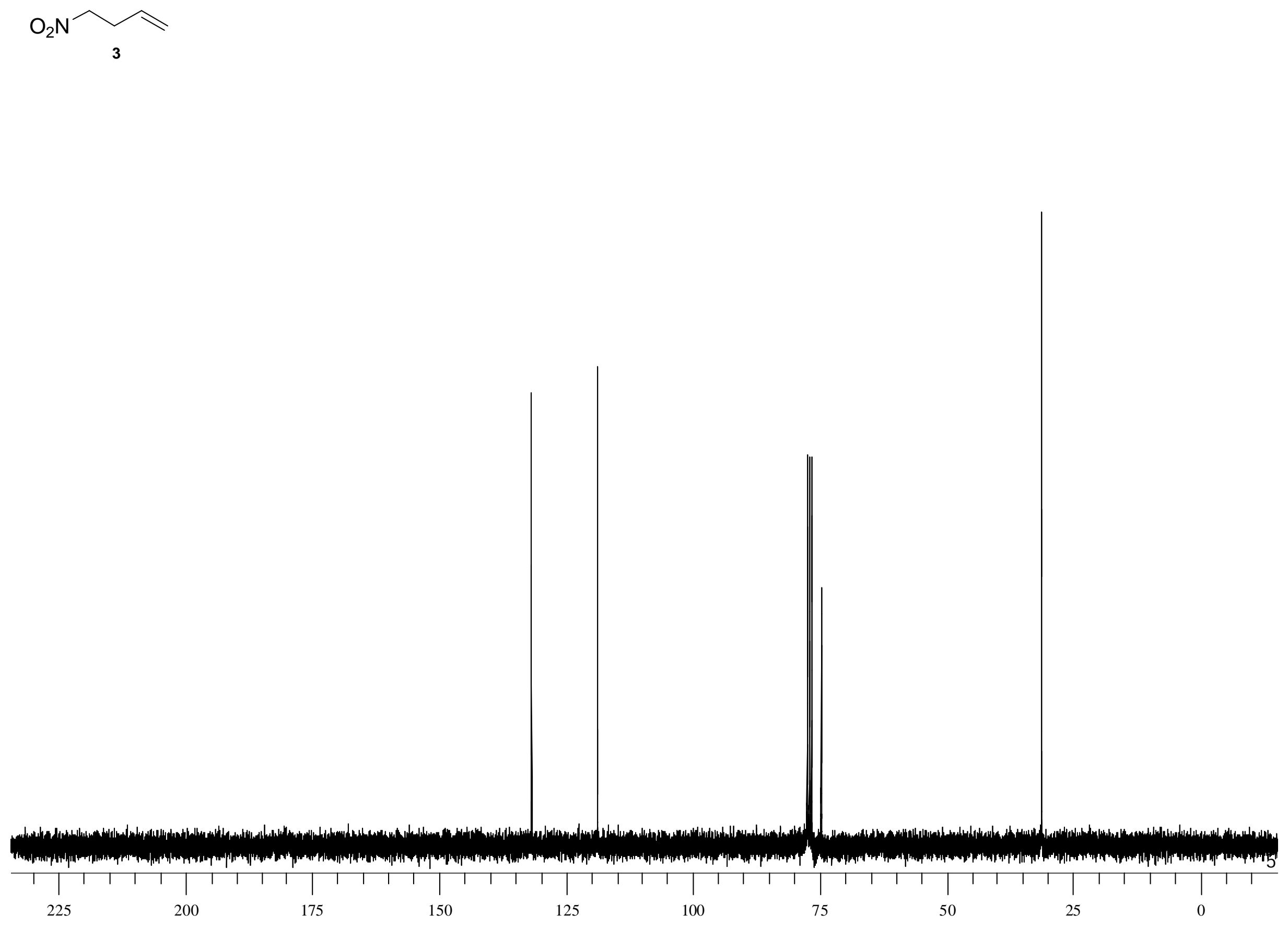

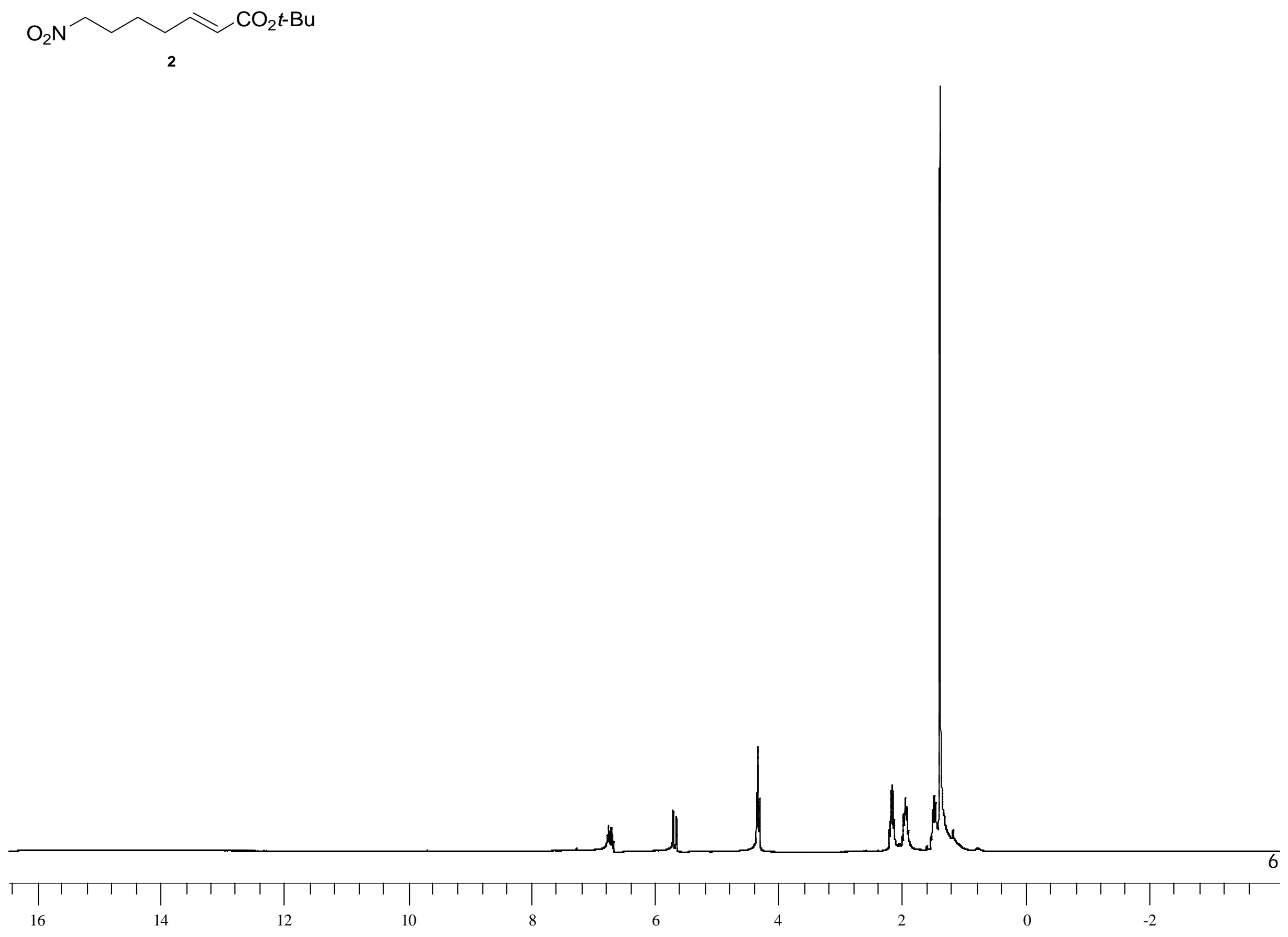


$$
\mathrm{O}_{2} \mathrm{~N} \overbrace{2}^{\mathrm{CO}_{2} t-\mathrm{Bu}}
$$

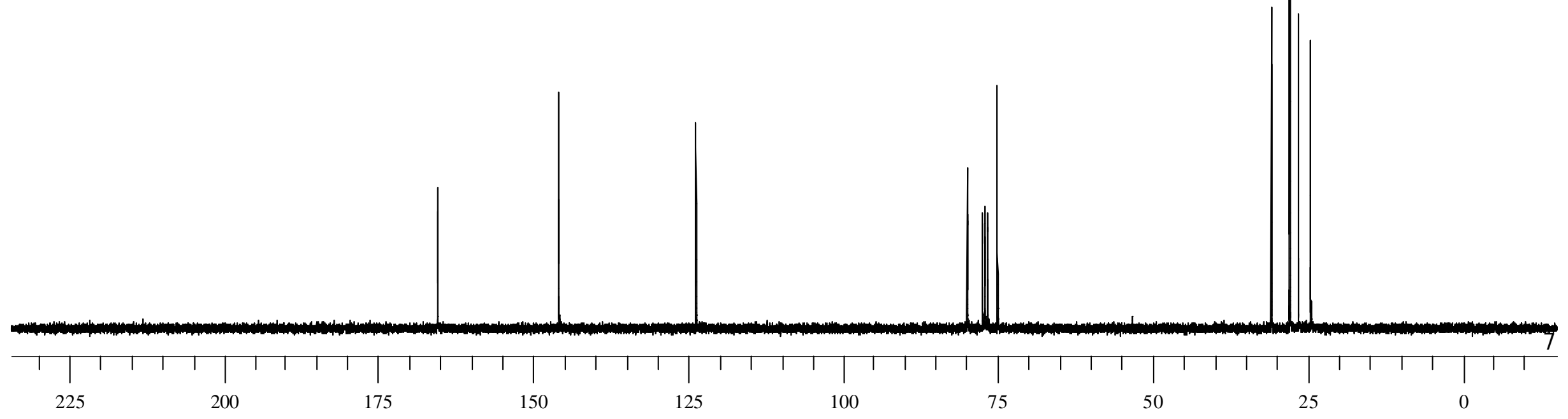



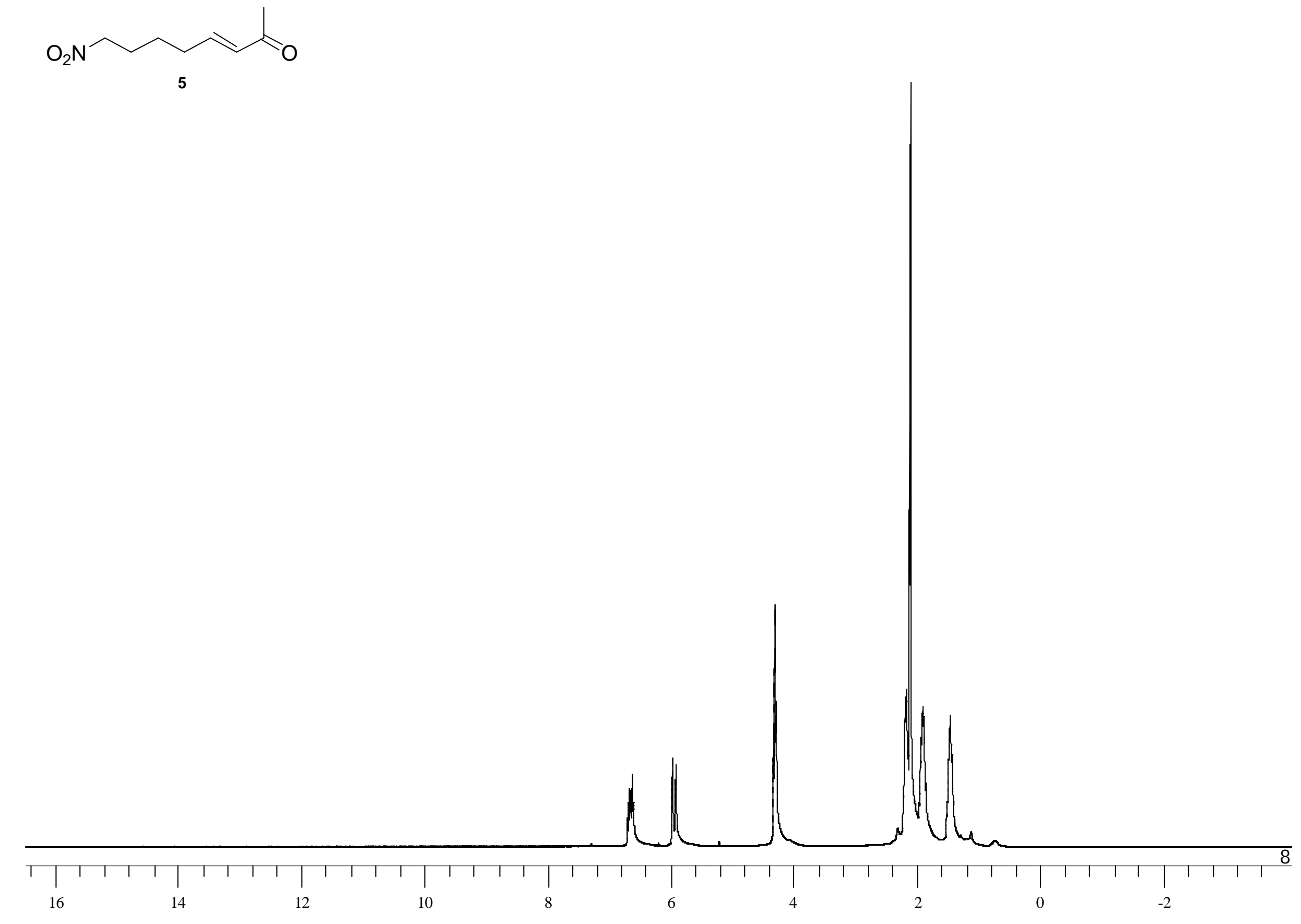

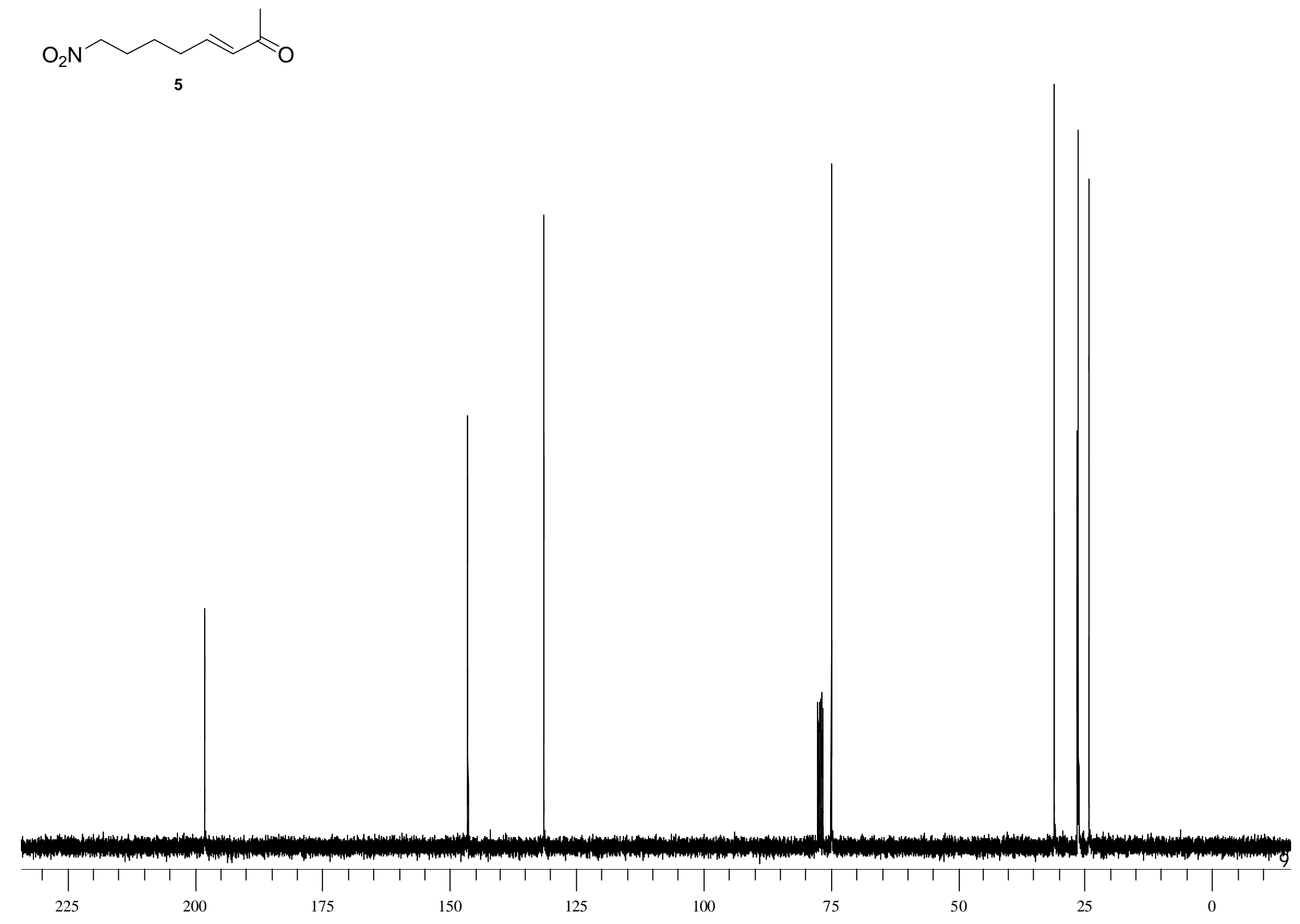

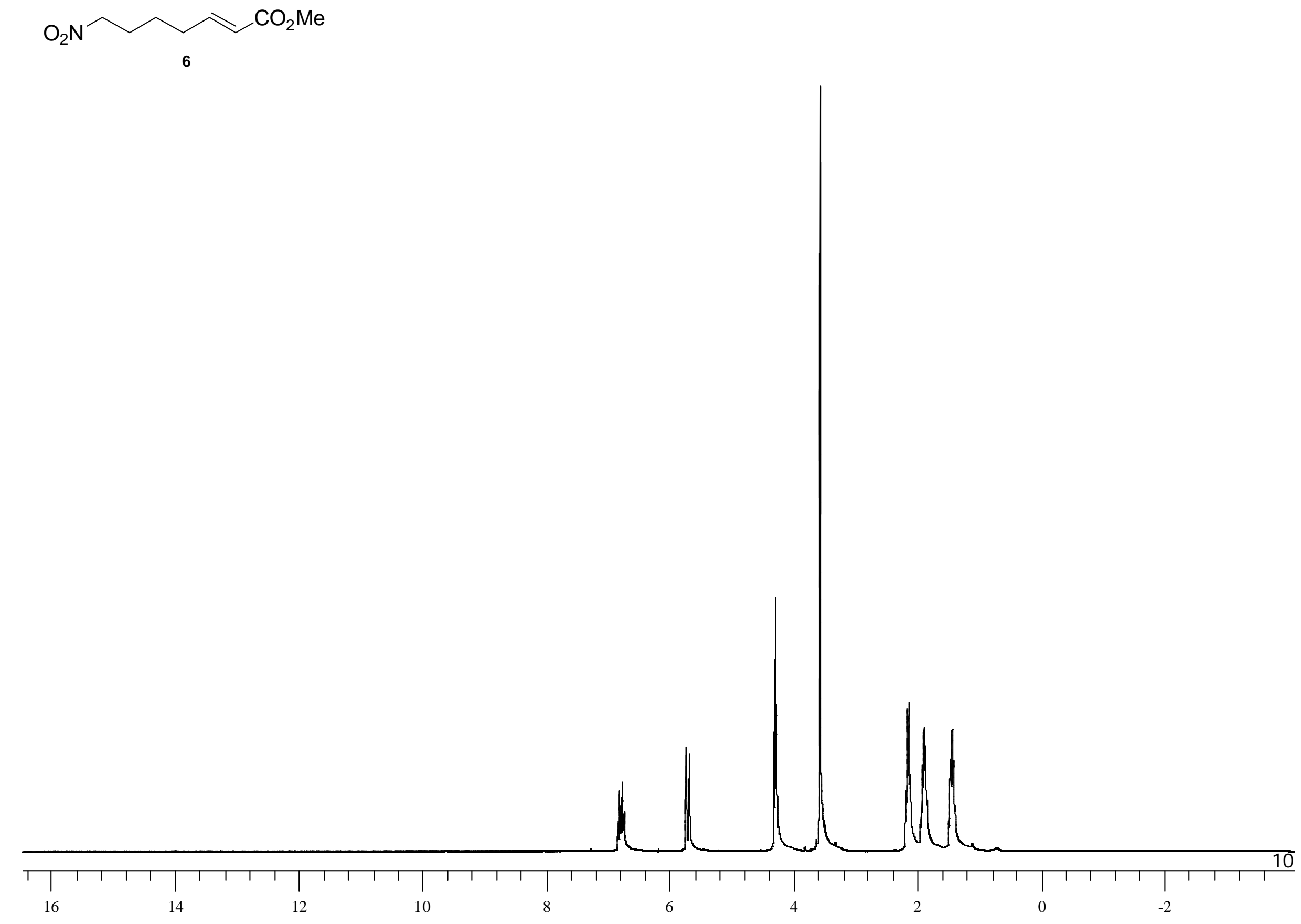

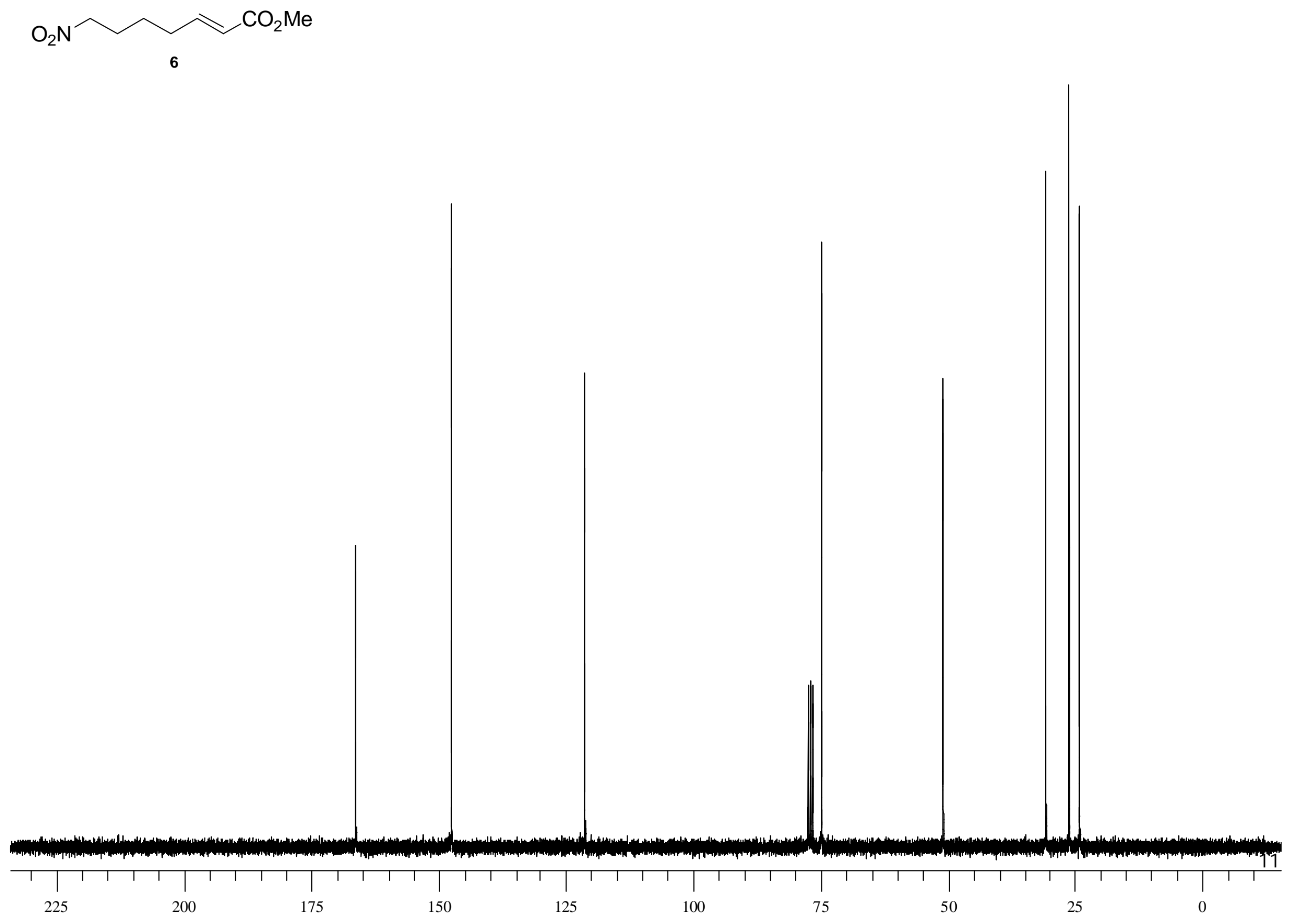
<smiles>O=CC=CCCCC[N+](=O)[O-]</smiles>

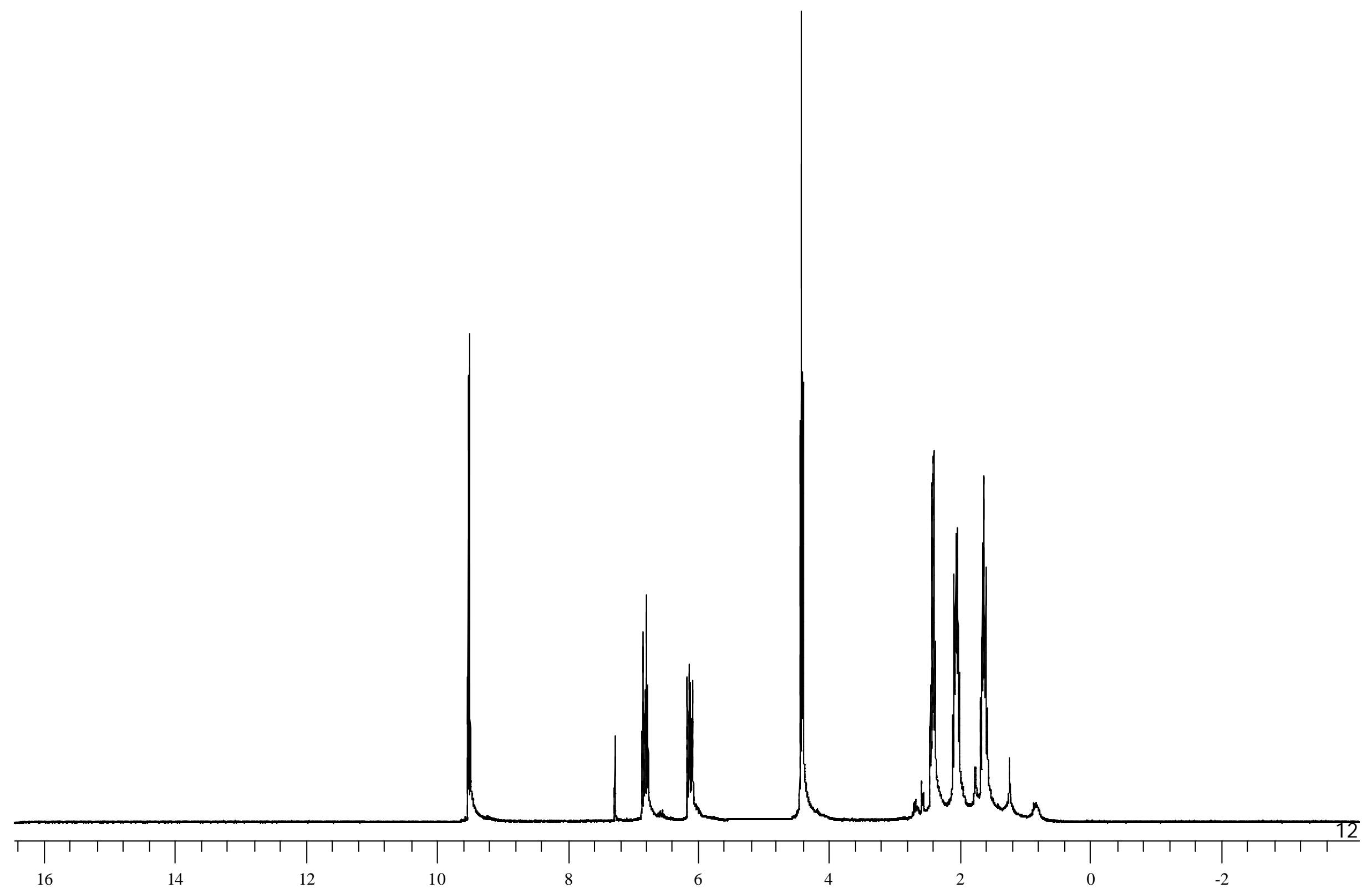



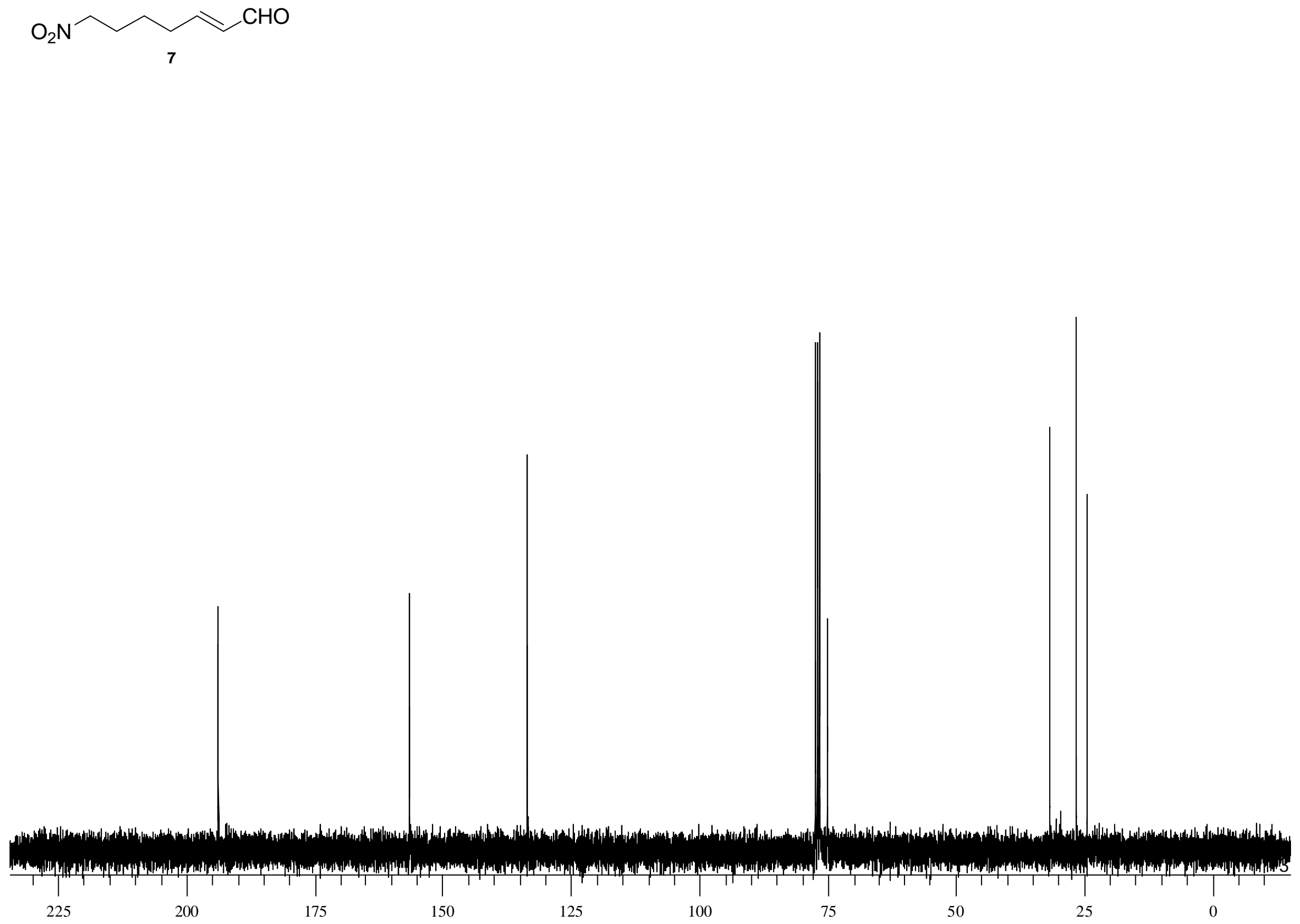


$$
\text { ancepos }
$$

$$
\text { Mal d wal }
$$



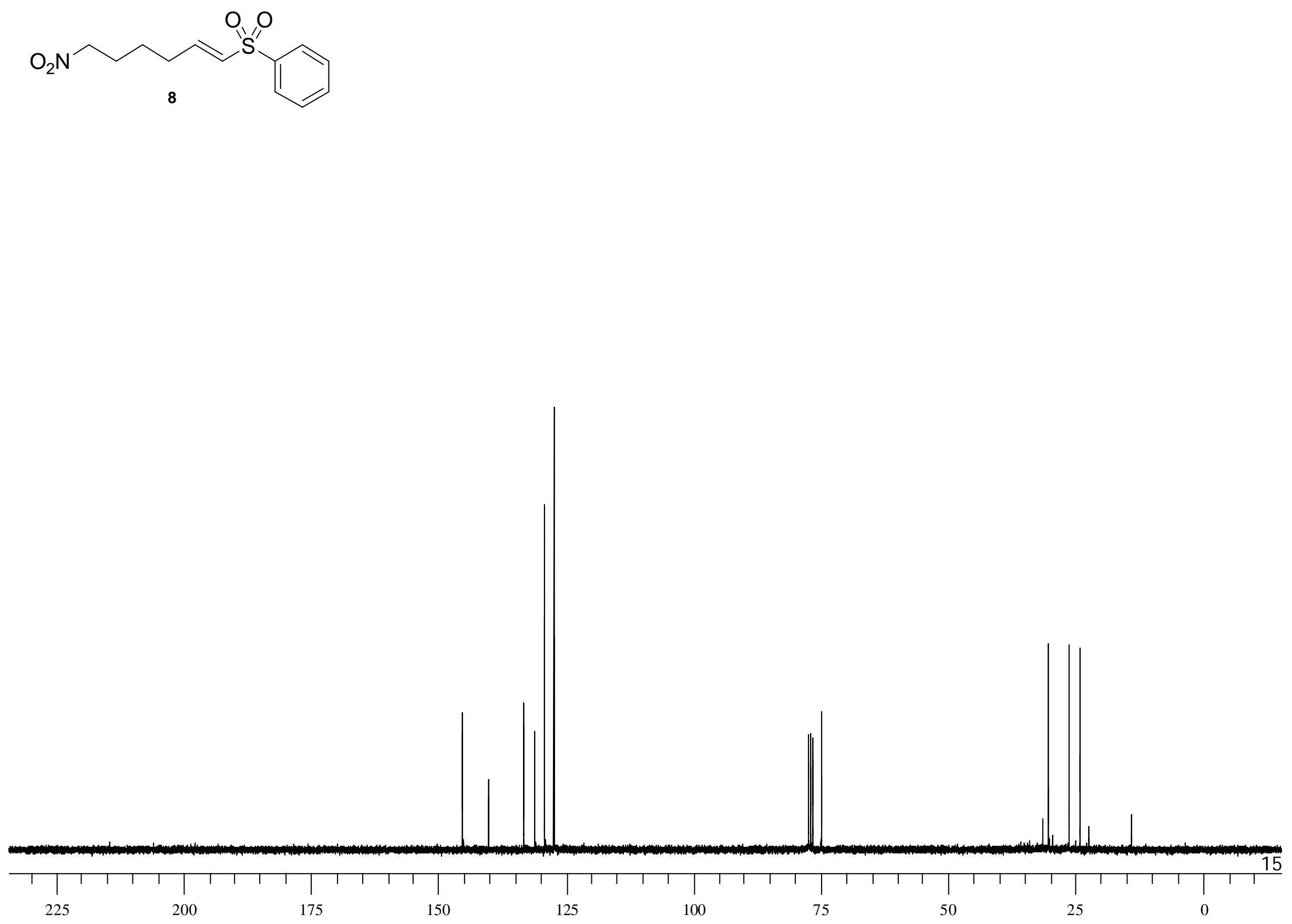


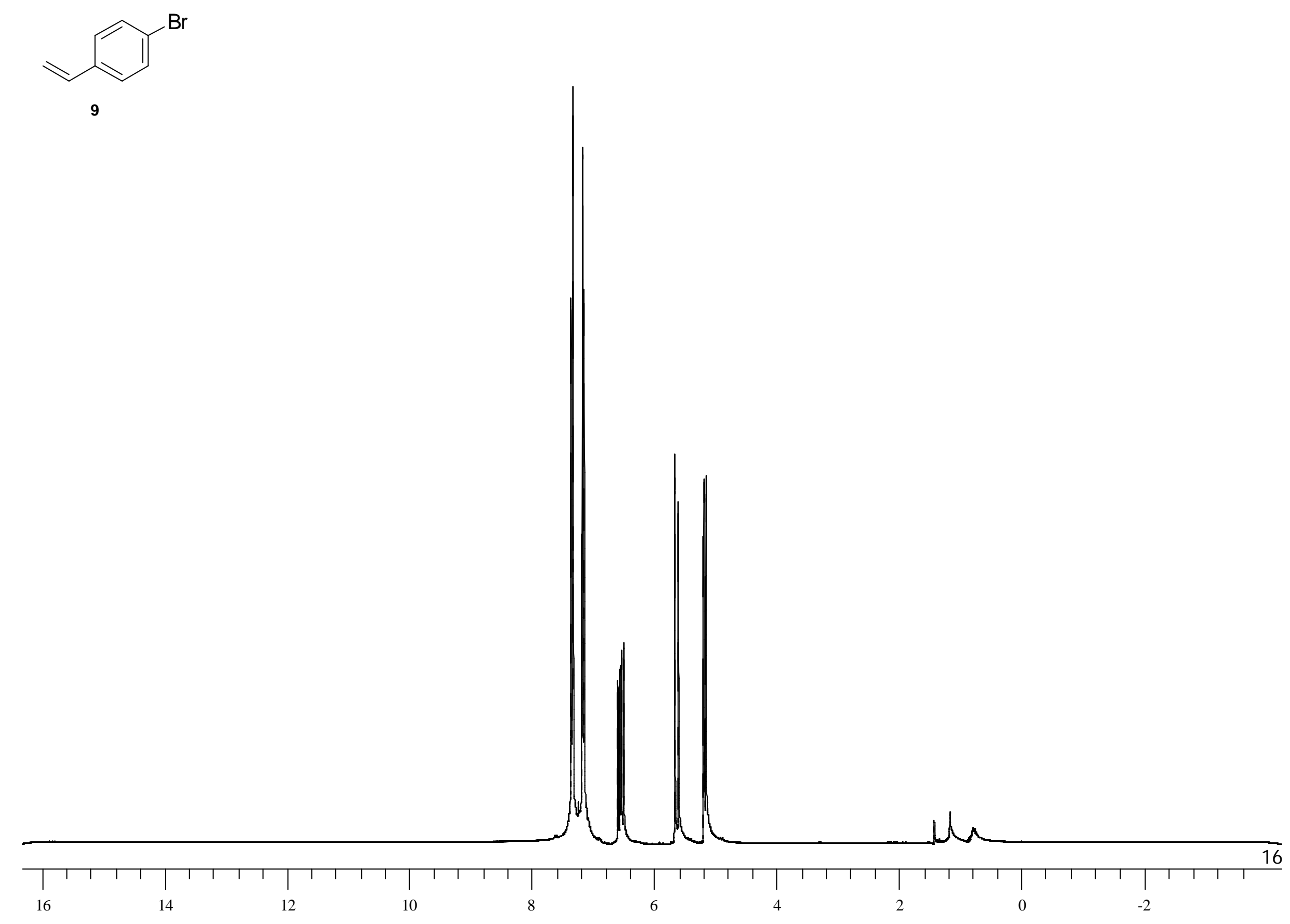




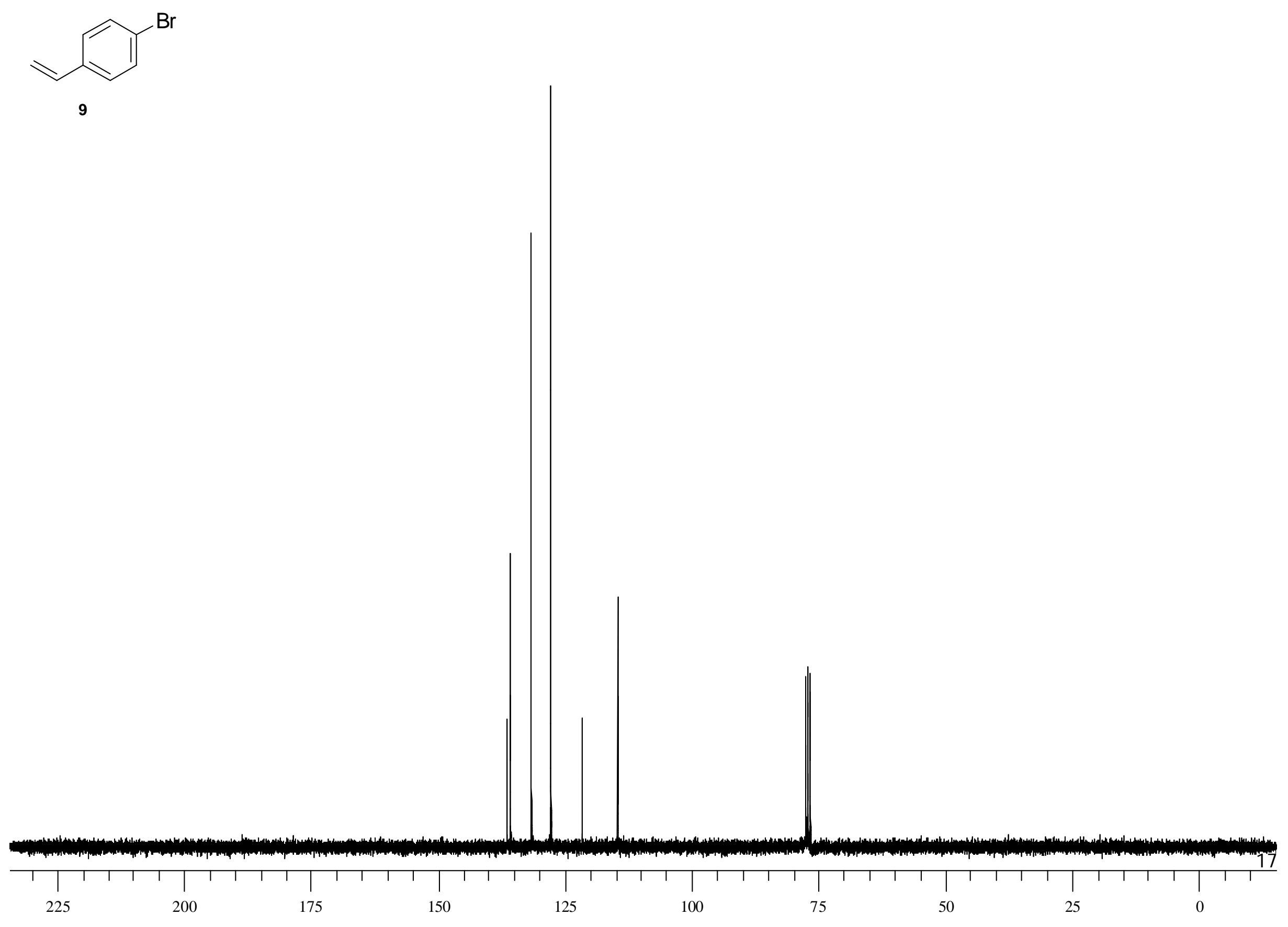



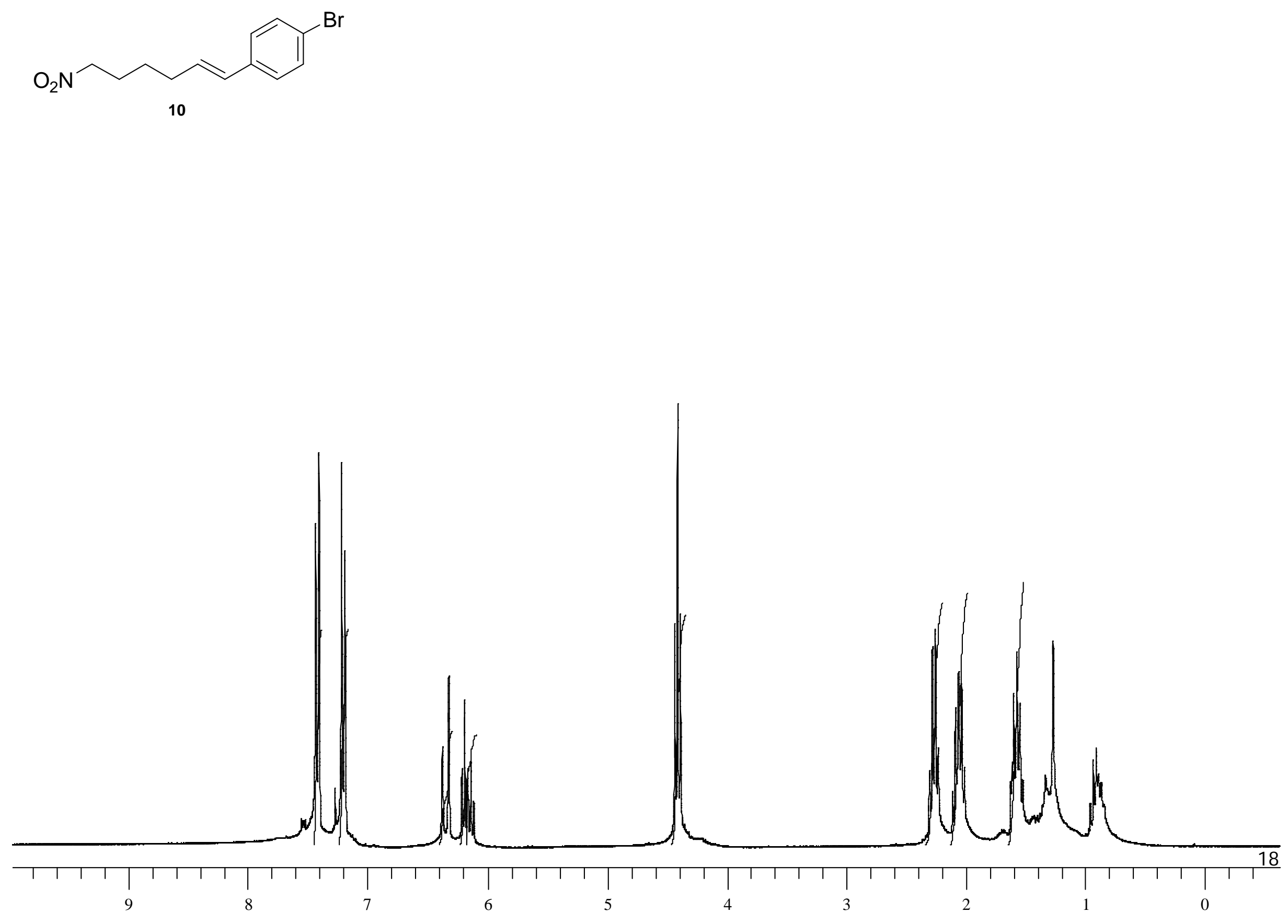

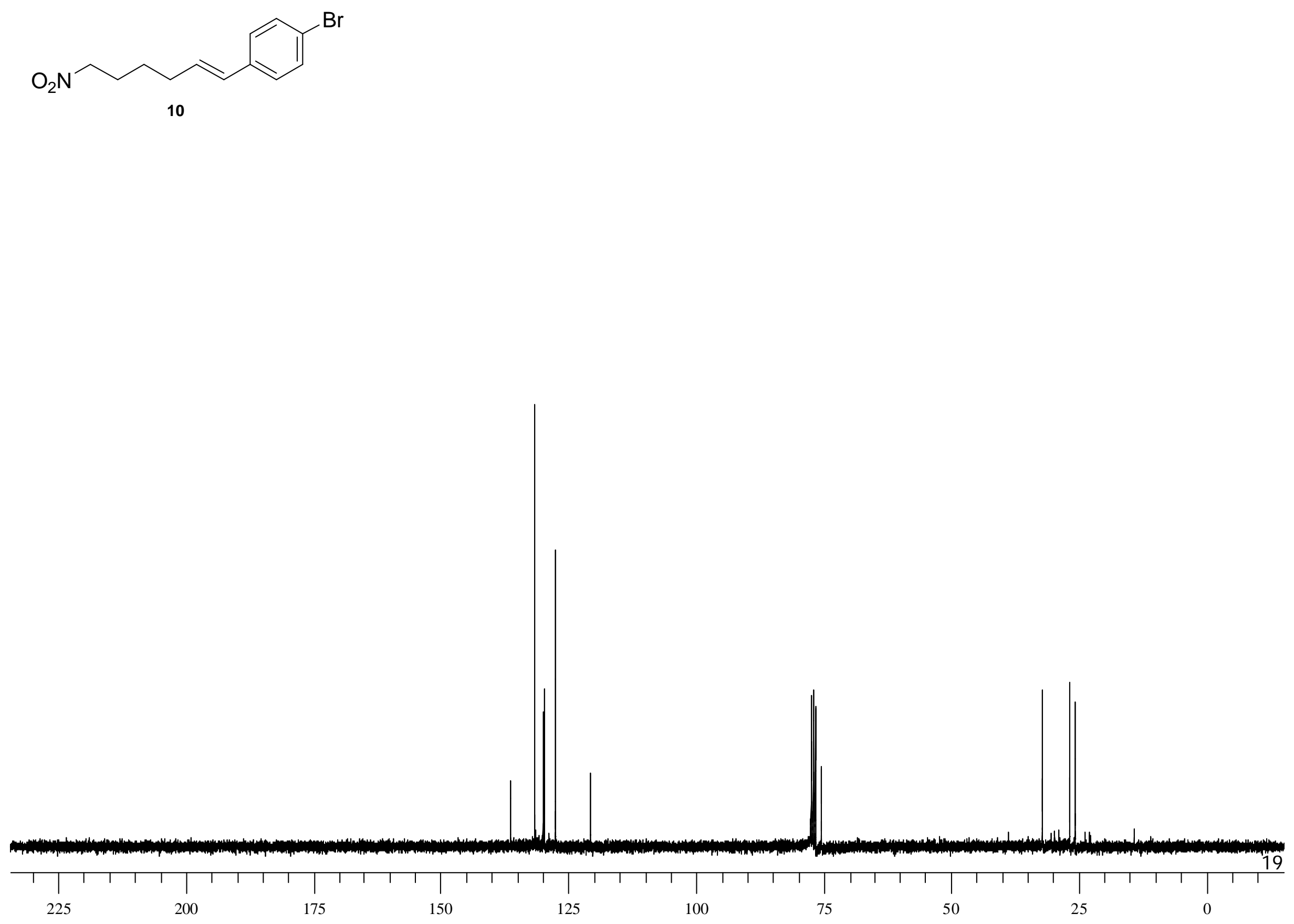


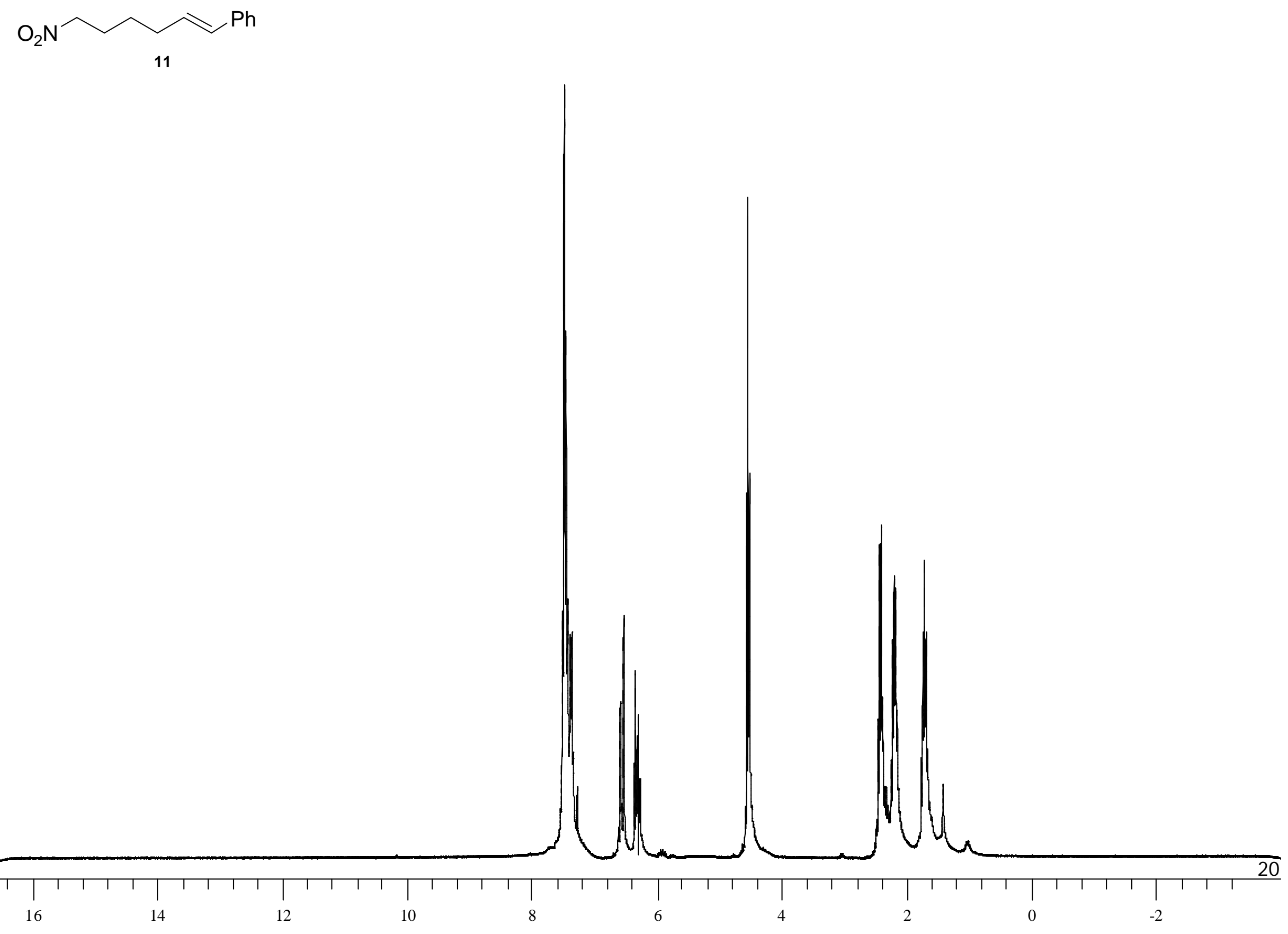



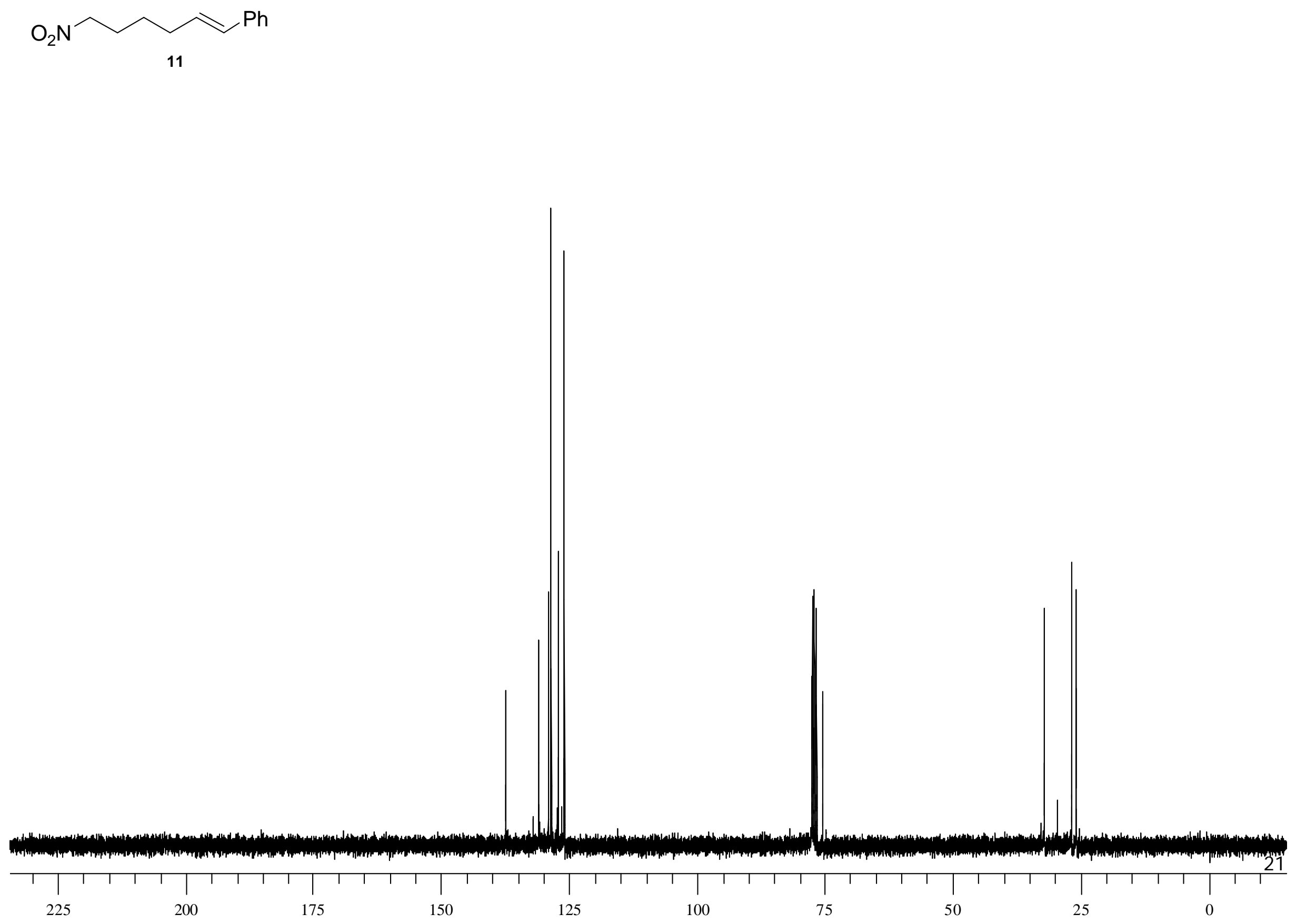


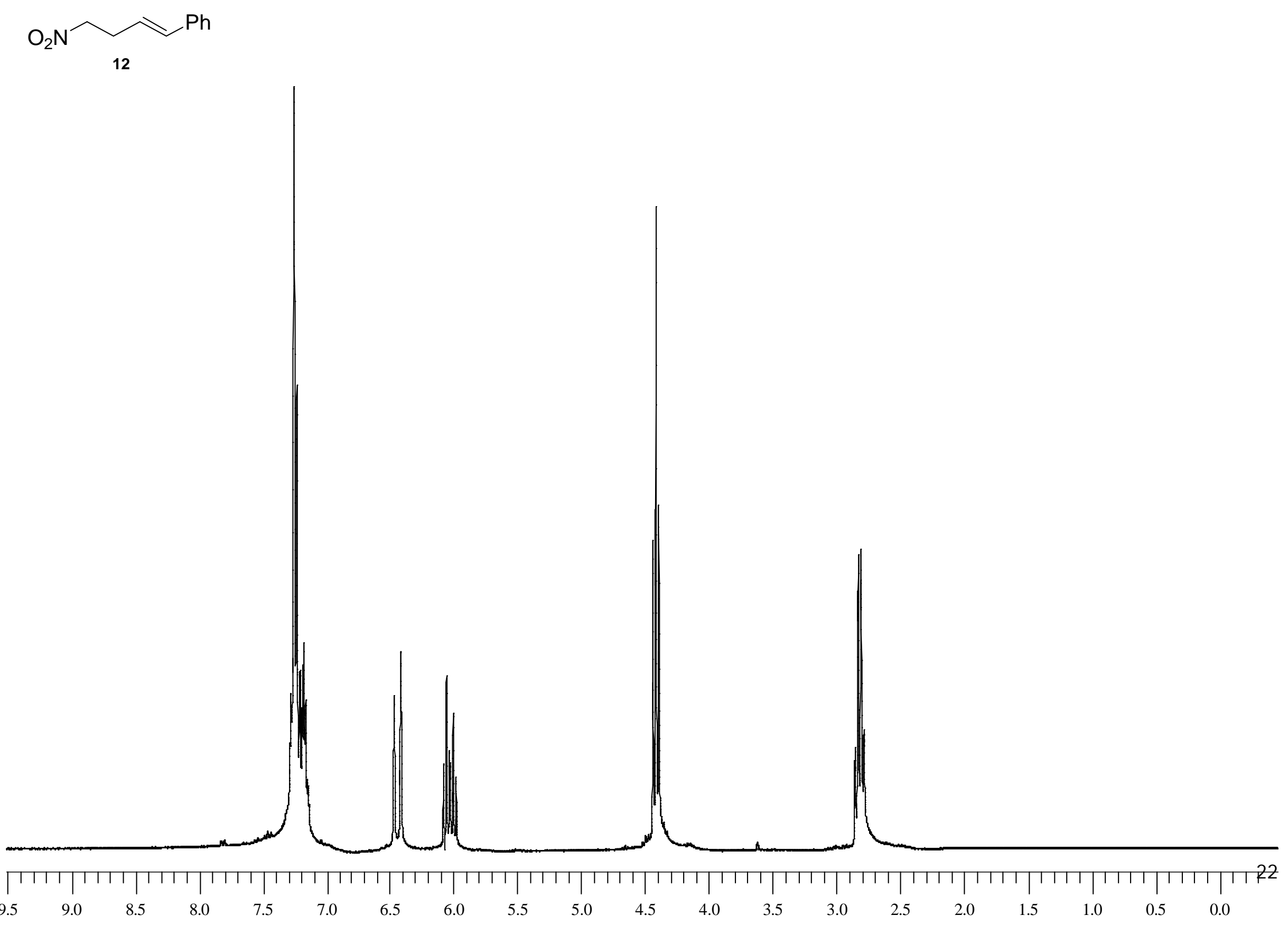




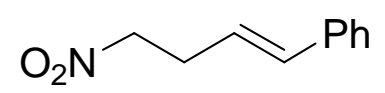

12

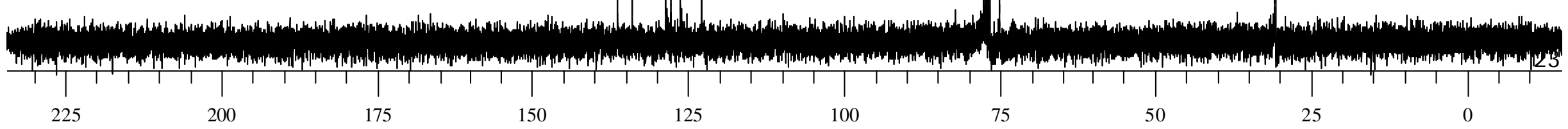




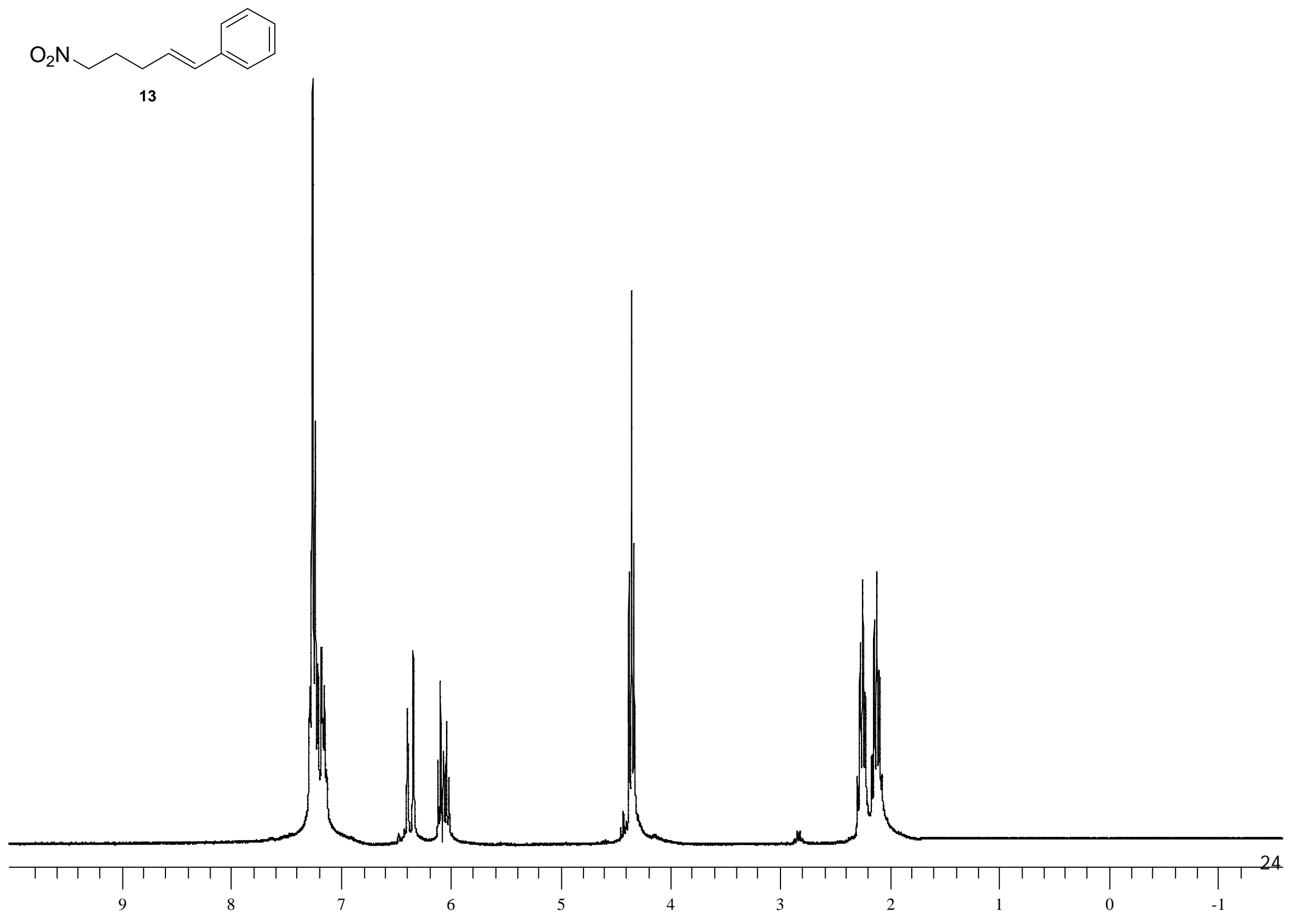




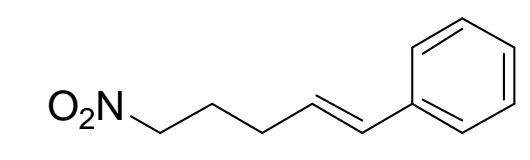

13

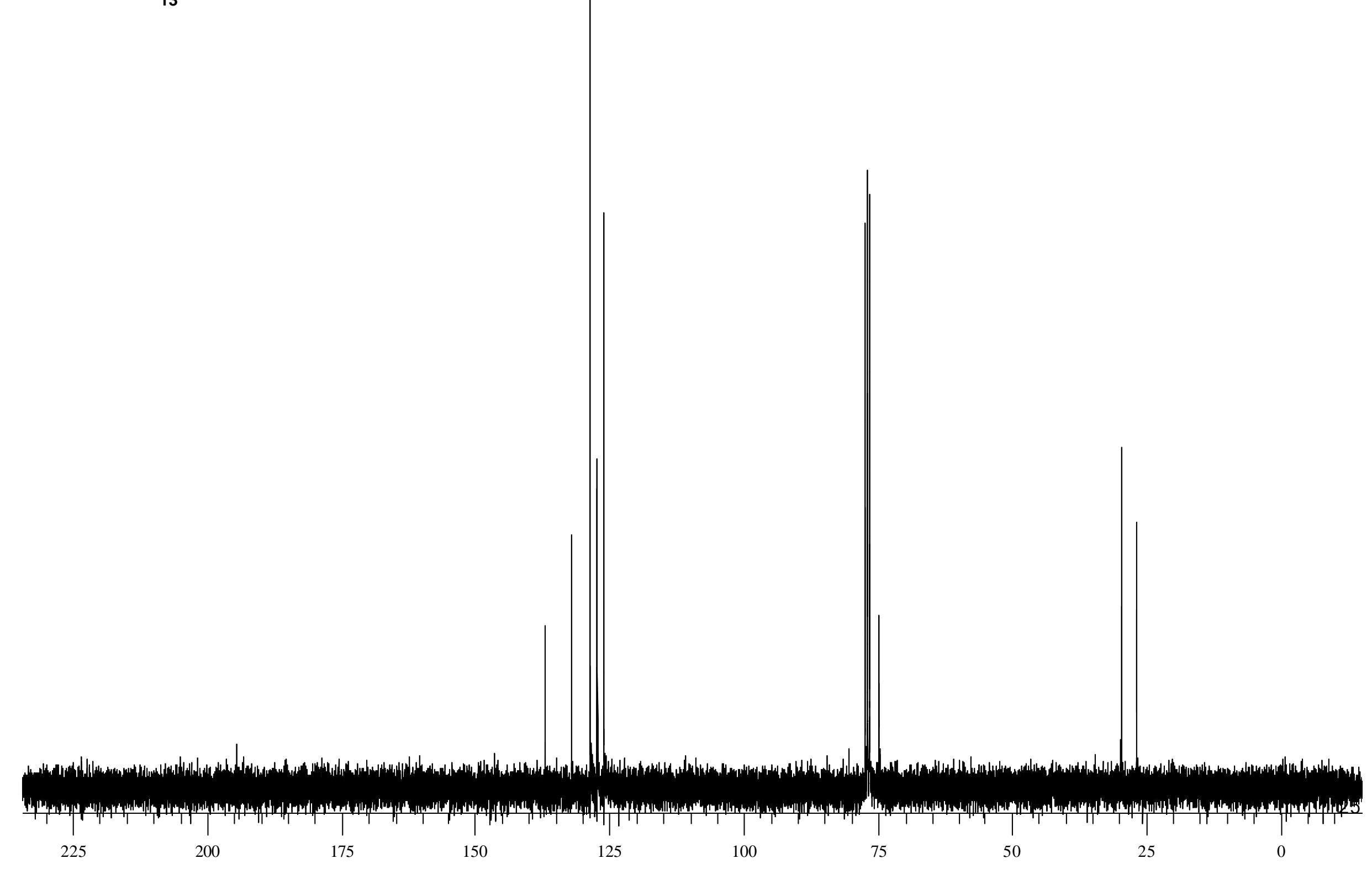




$$
\text { b. }
$$




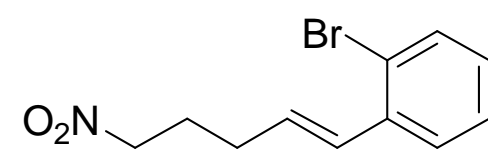

14

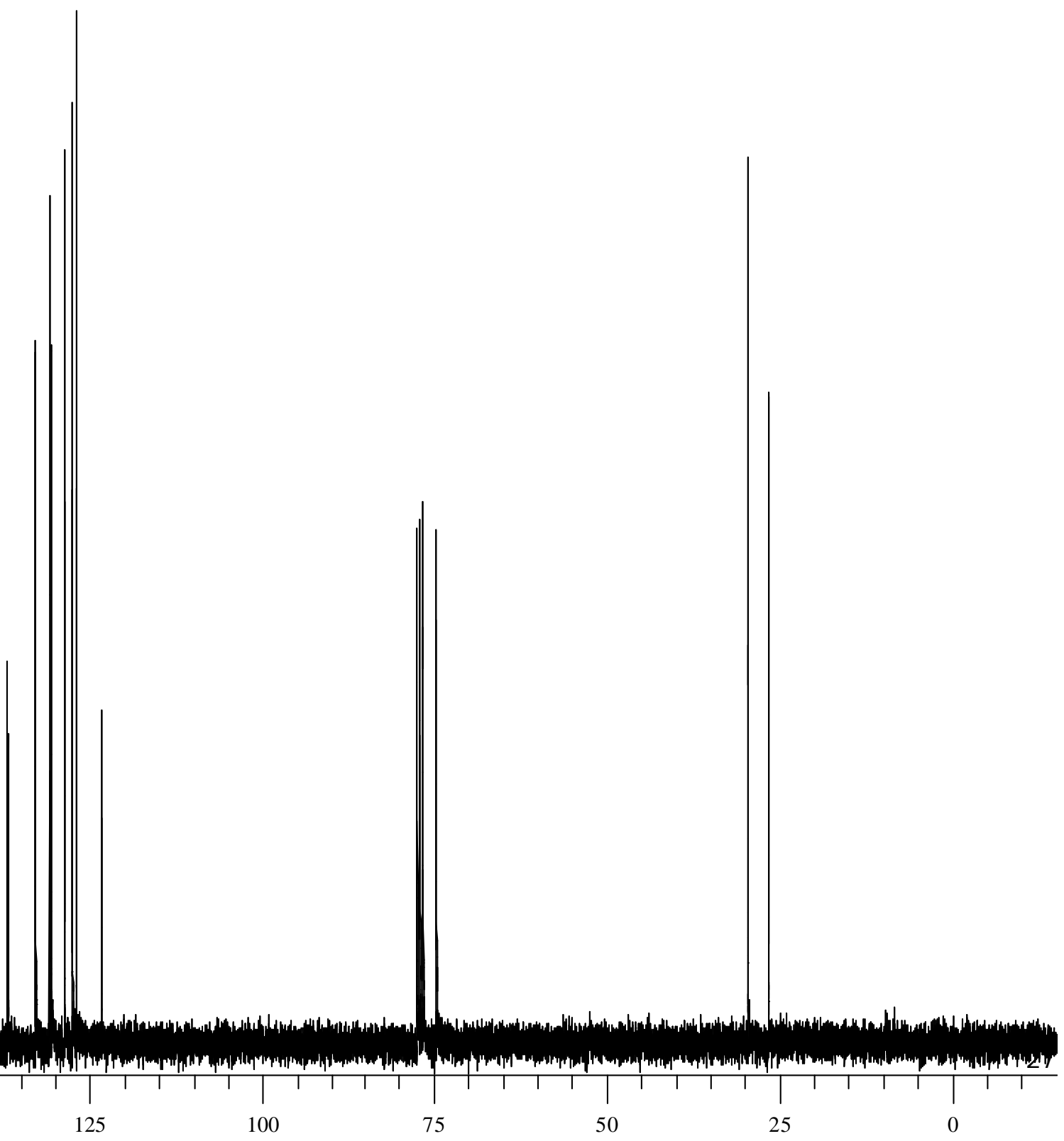




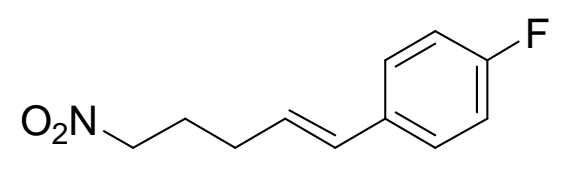

15

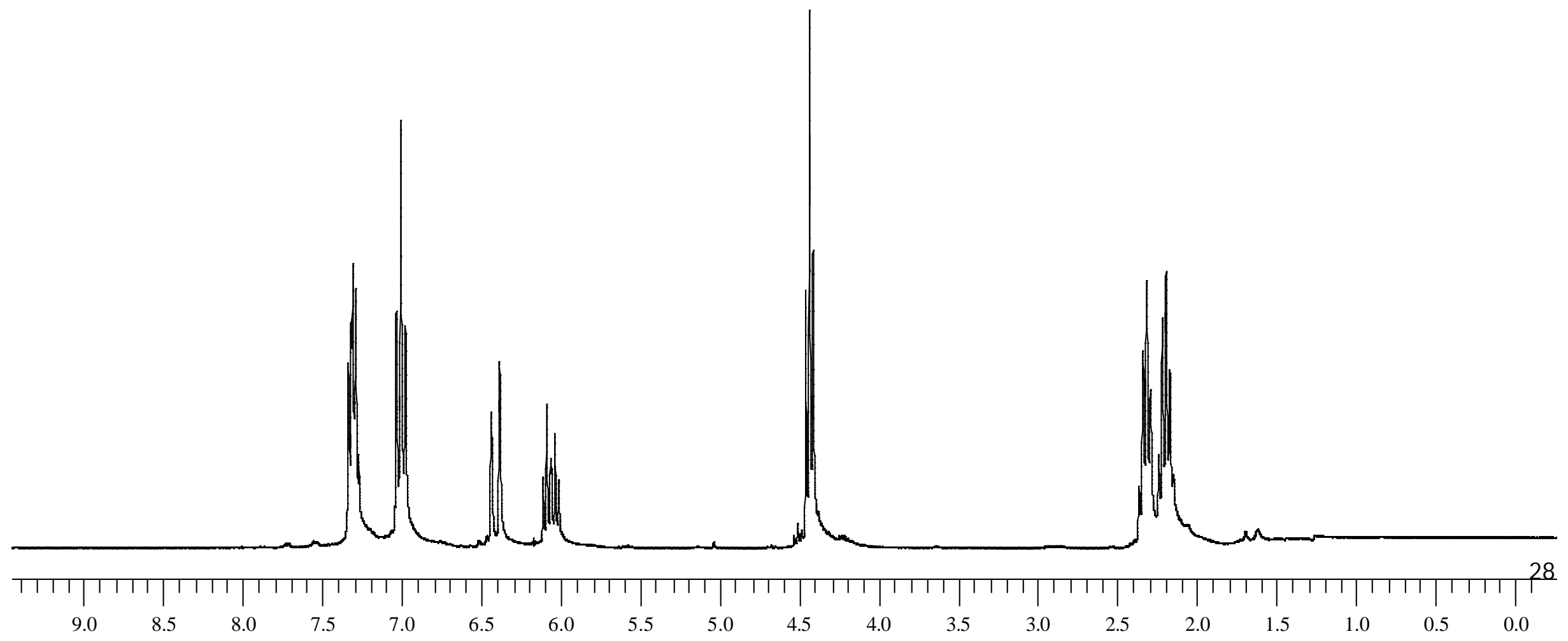




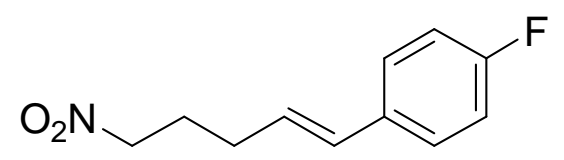

15

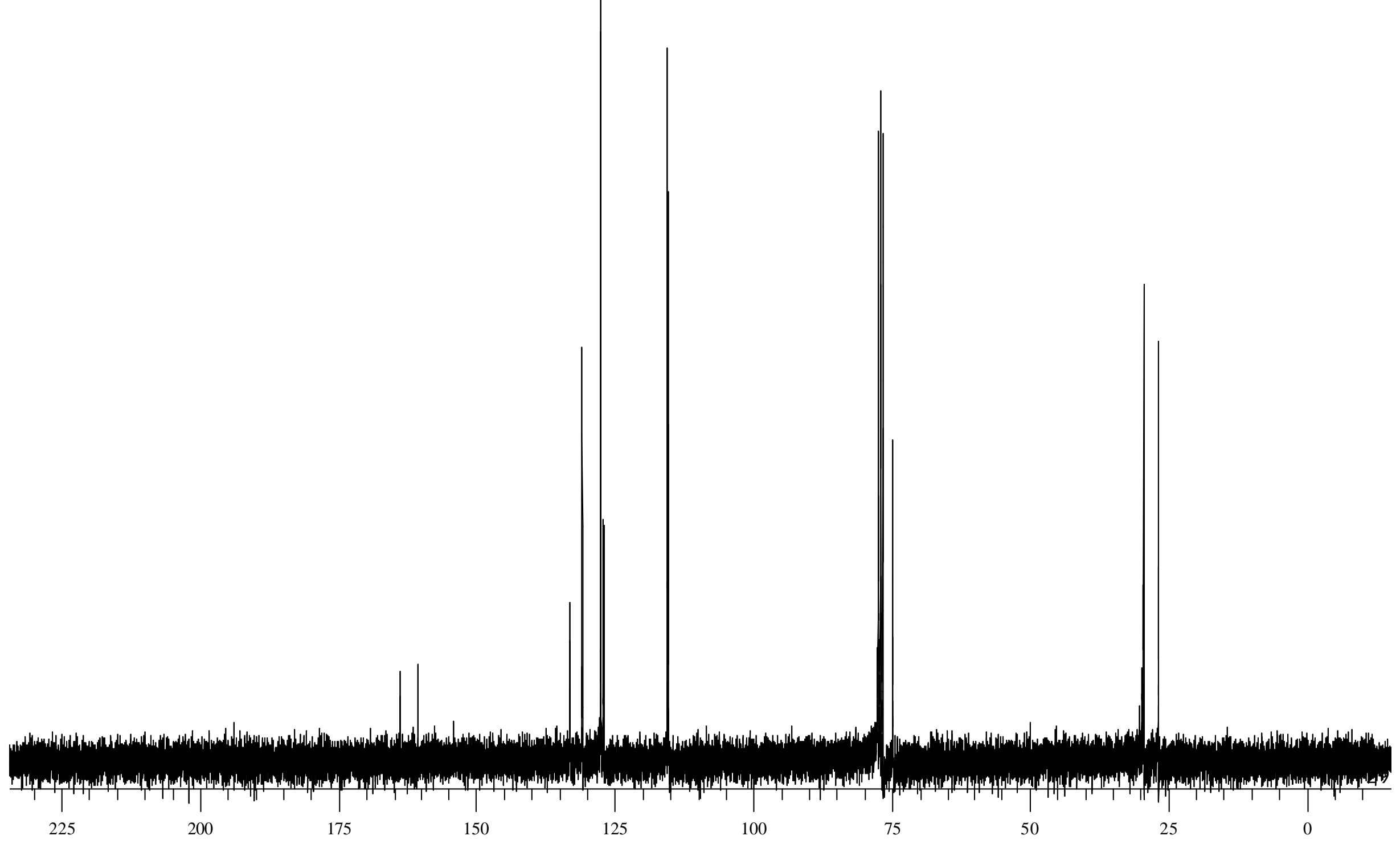


$\mathrm{O}_{2} \mathrm{~N} \sim_{16}^{\mathrm{Br}}$

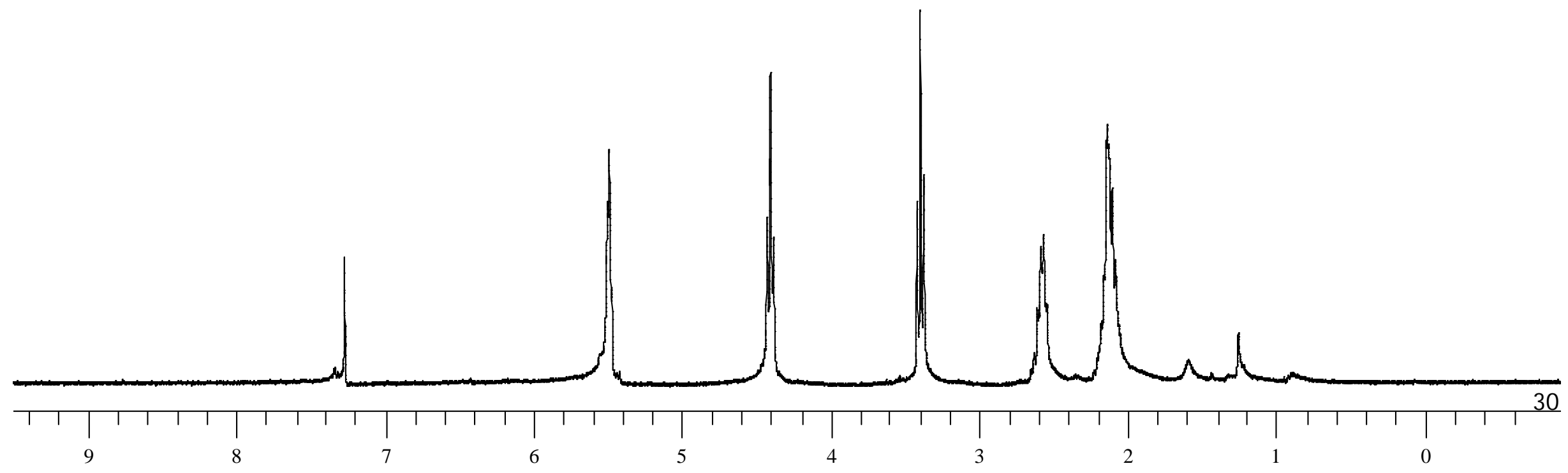


$\mathrm{O}_{2} \mathrm{~N}$ $\mathrm{Br}$

16

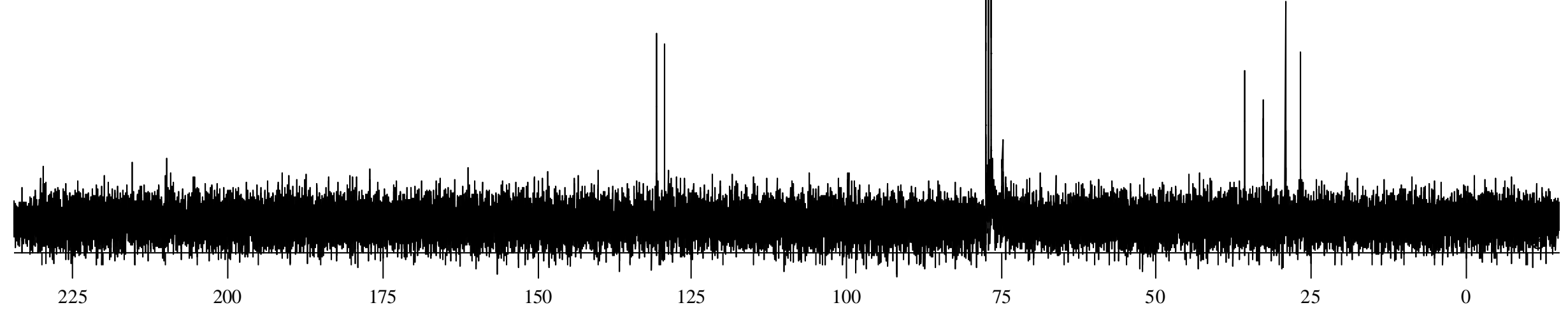



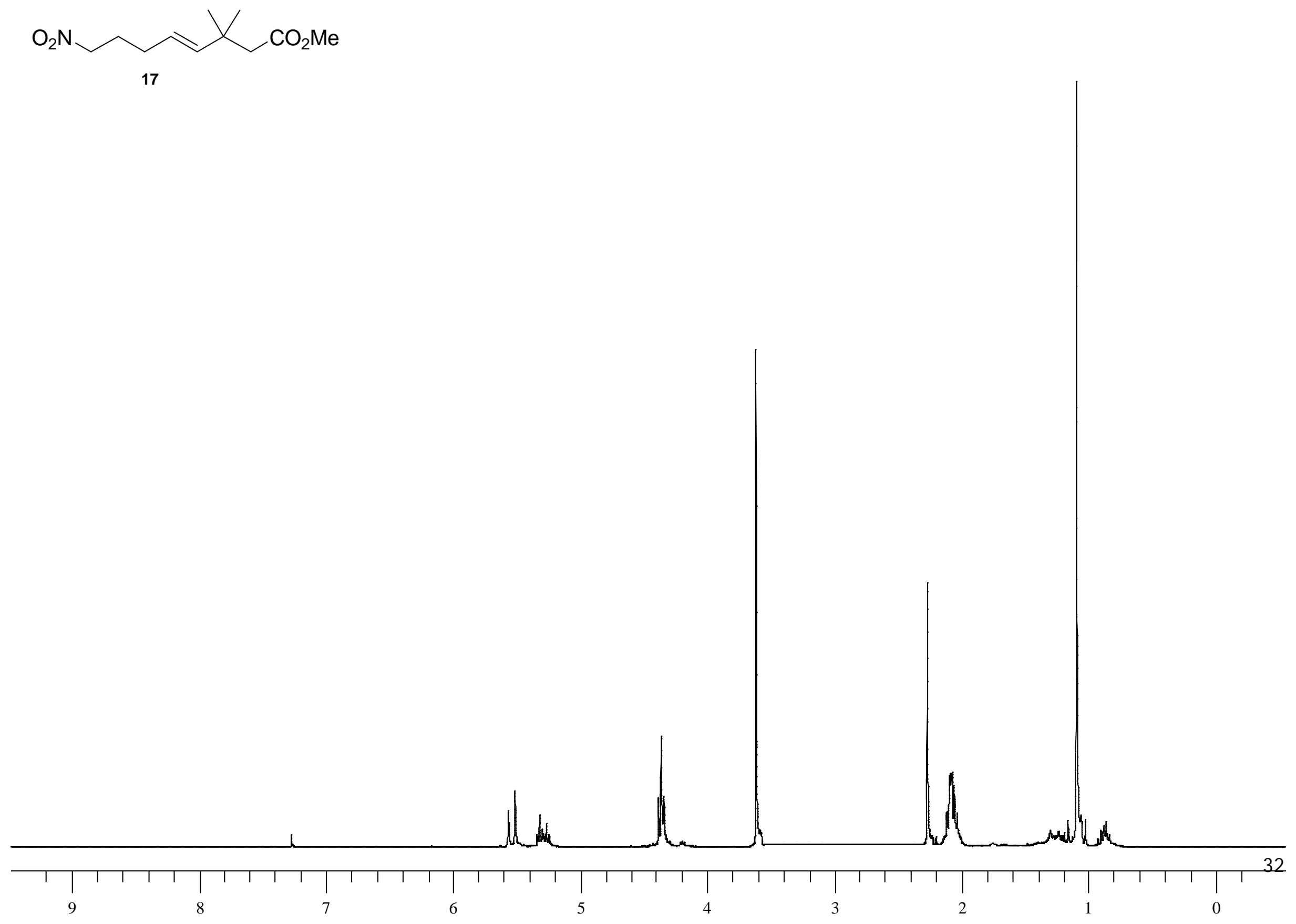

$\mathrm{O}_{2} \mathrm{~N} \sim \mathrm{CO}_{2} t \mathrm{Bu}$

18

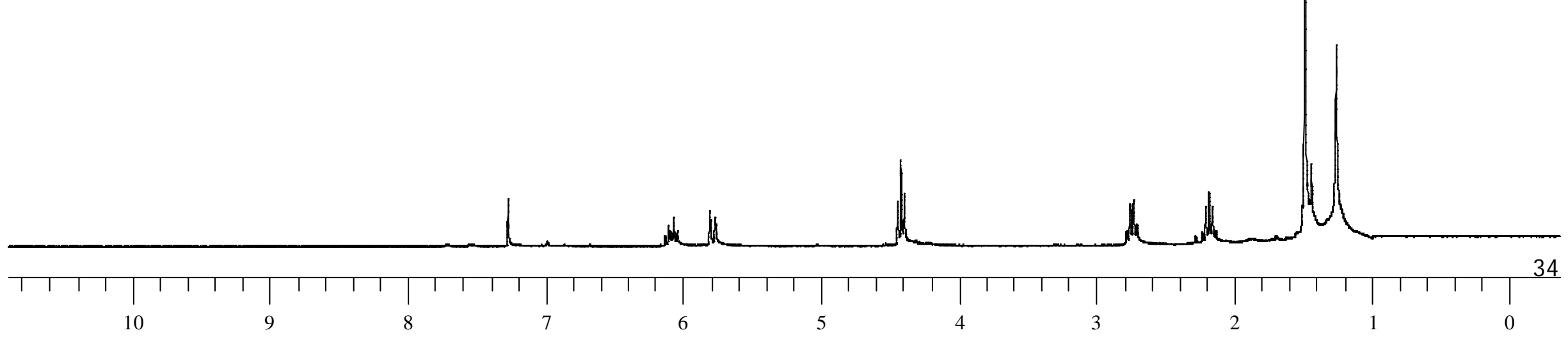


$\mathrm{O}_{2} \mathrm{~N} \sim \mathrm{CO}_{2} t-\mathrm{Bu}$

18

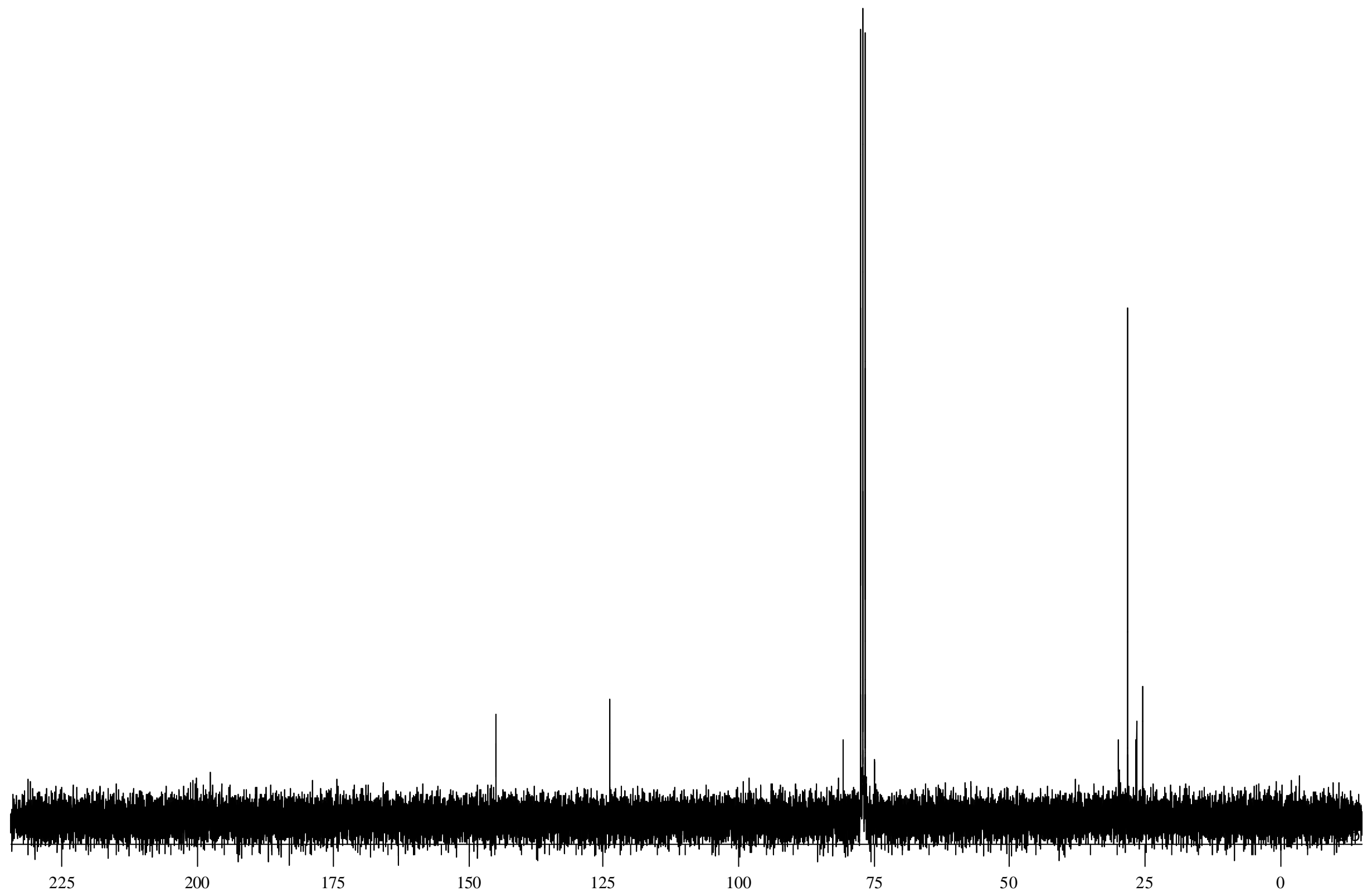


$\mathrm{O}_{2} \mathrm{~N} \sim \mathrm{CO}_{2} \mathrm{Me}$

19

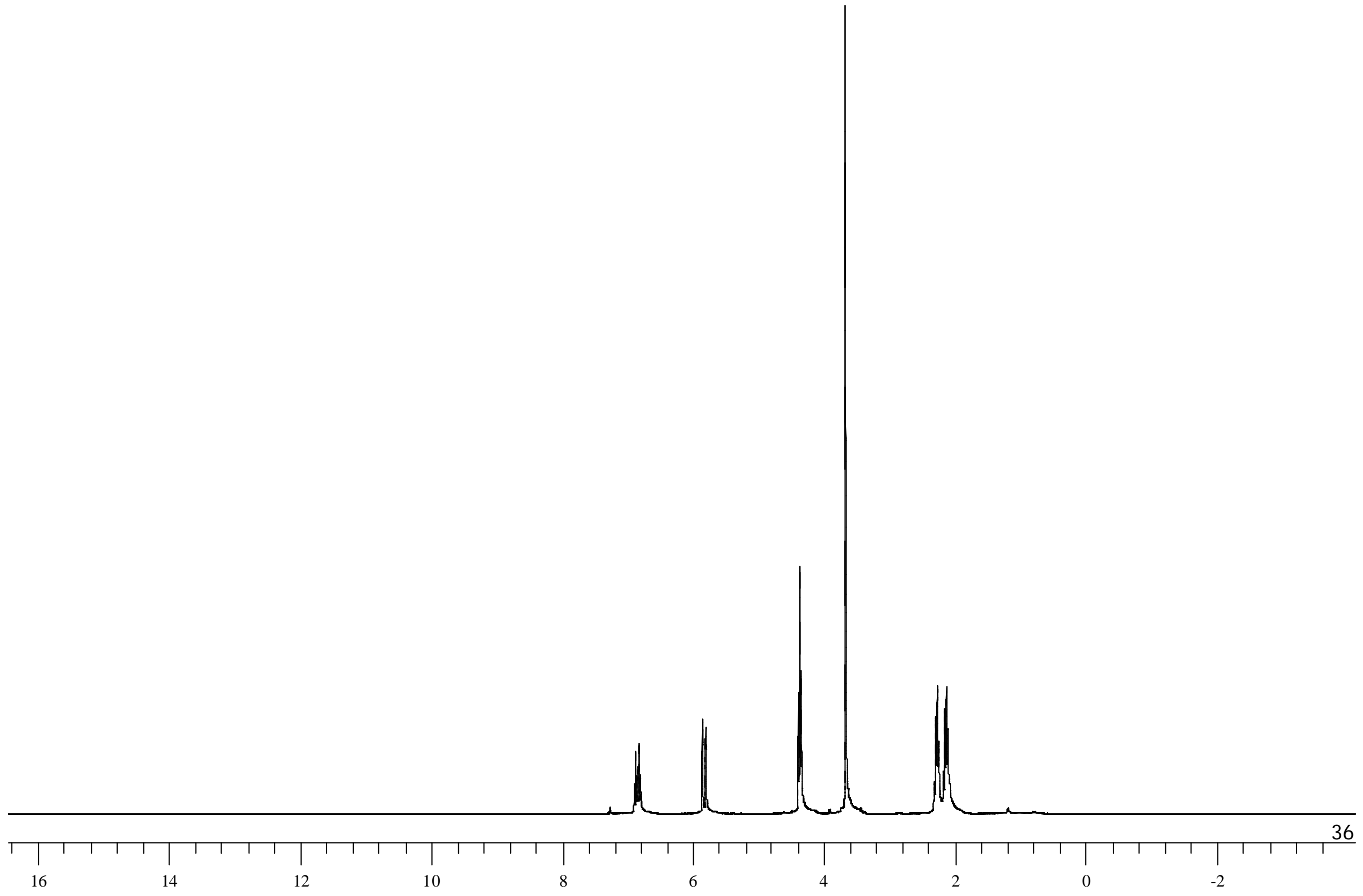


$\mathrm{O}_{2} \mathrm{~N} \sim \mathrm{CO}_{2} \mathrm{Me}$

19

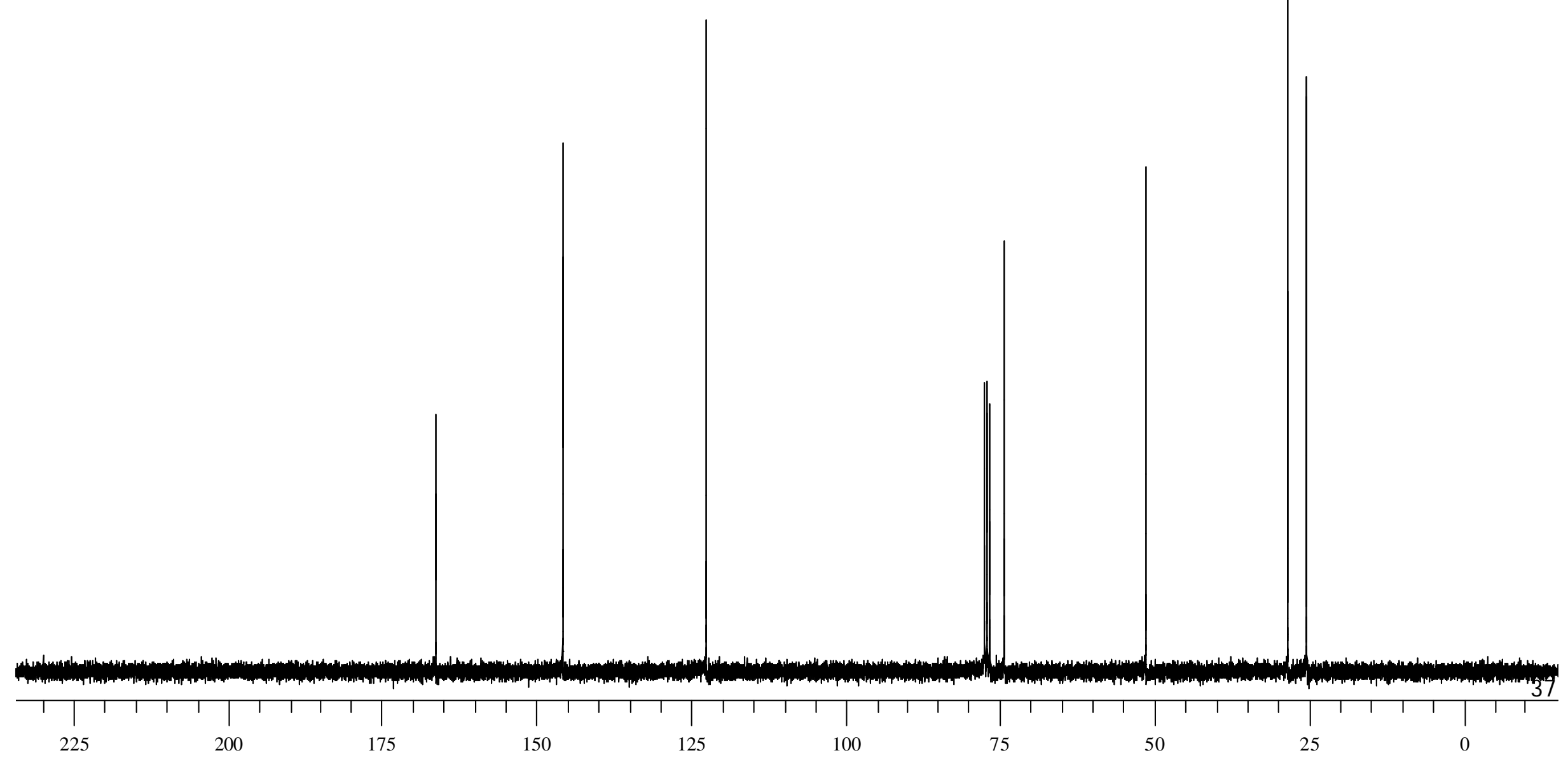




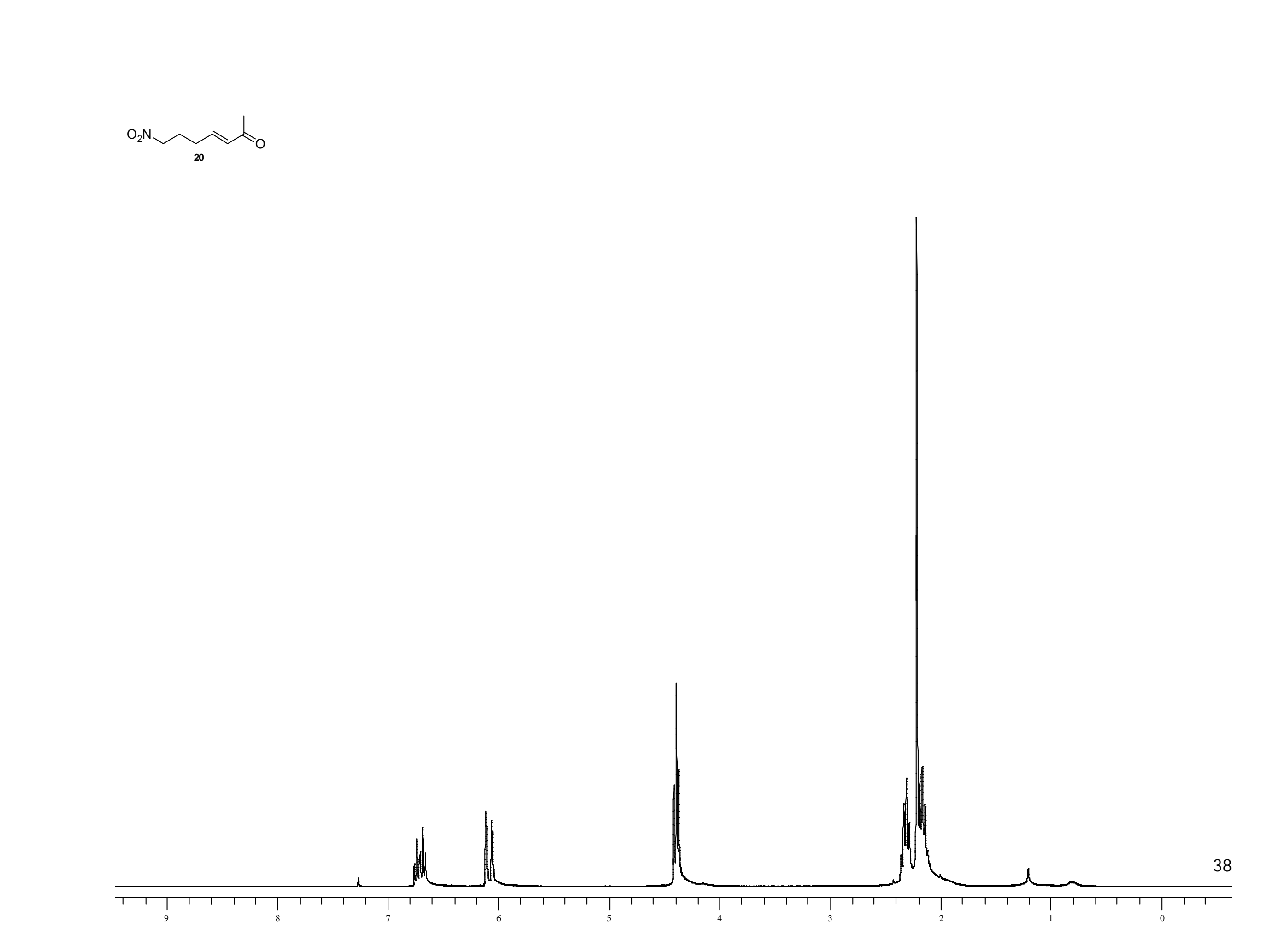





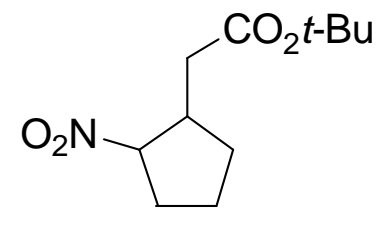

21

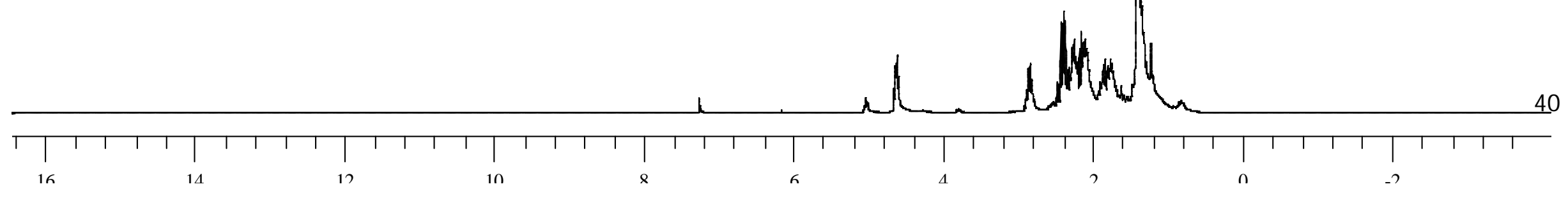



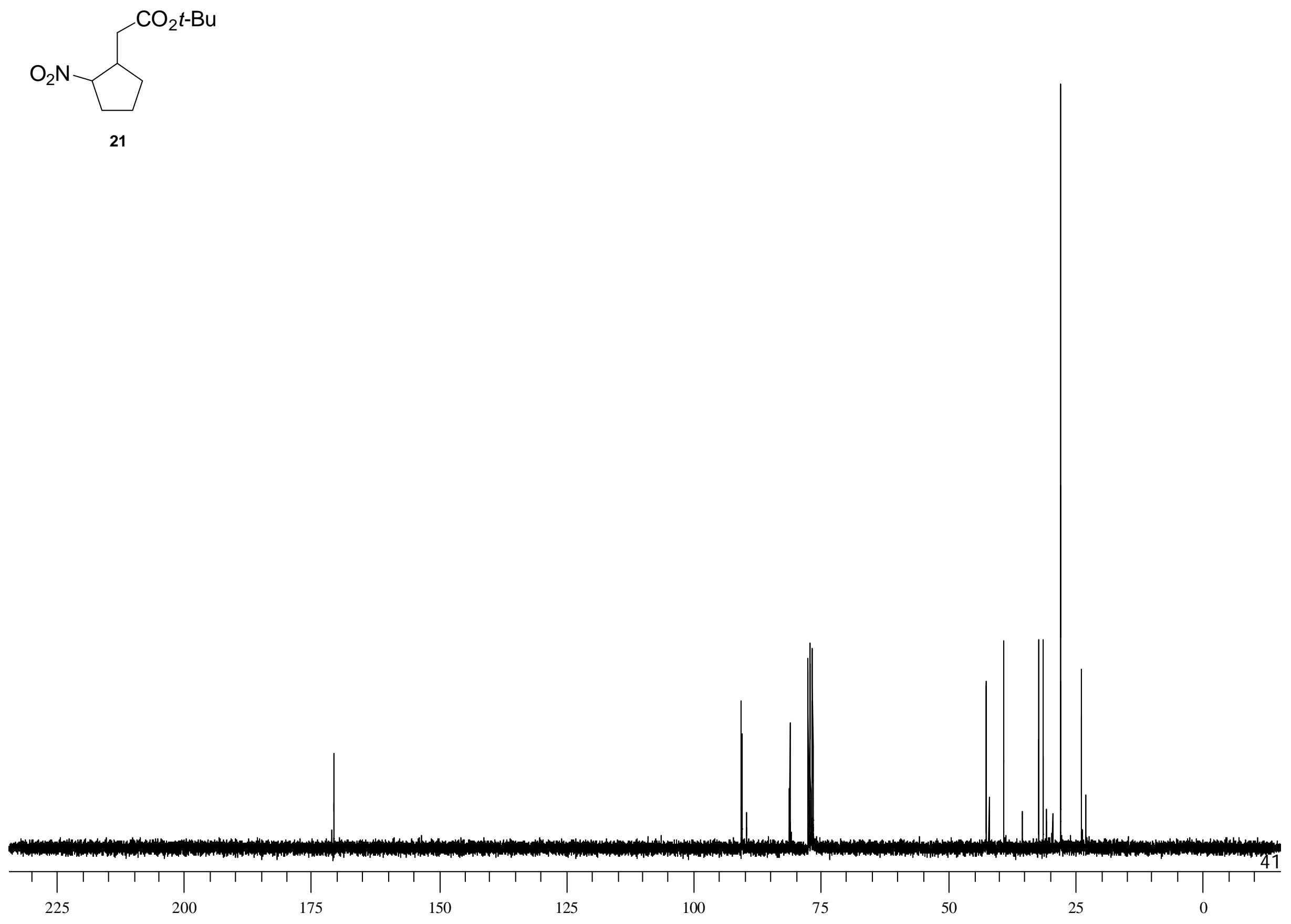

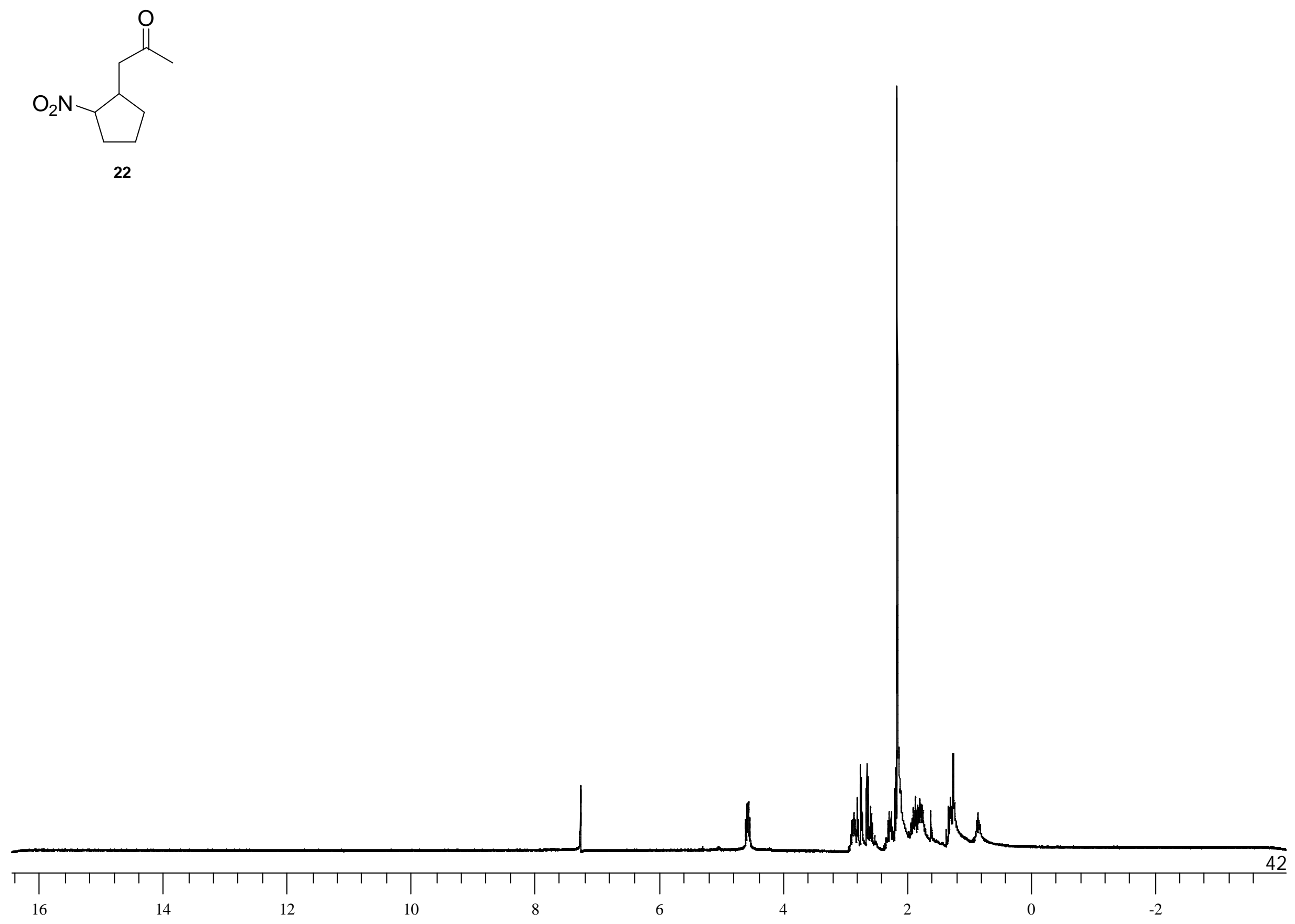



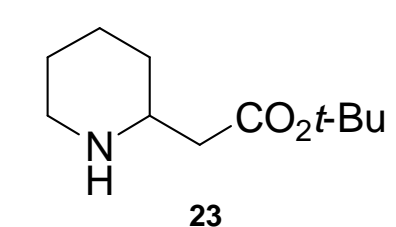

23

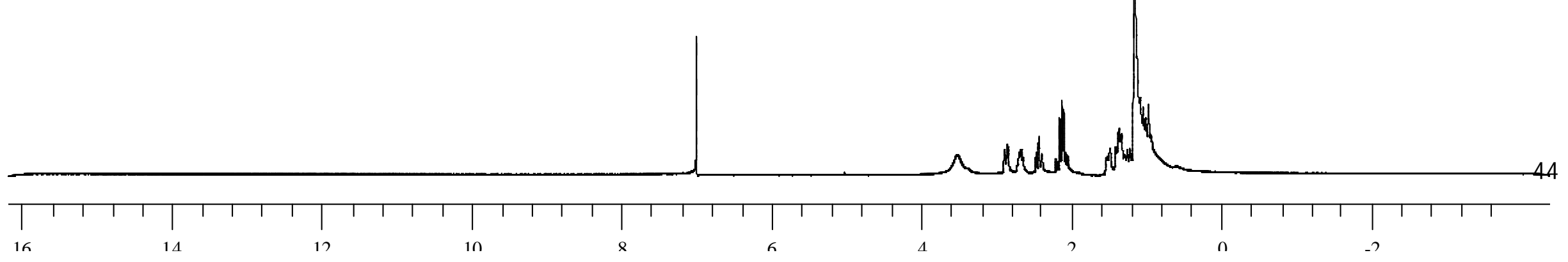




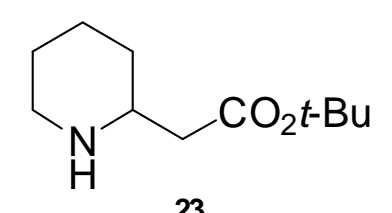

23

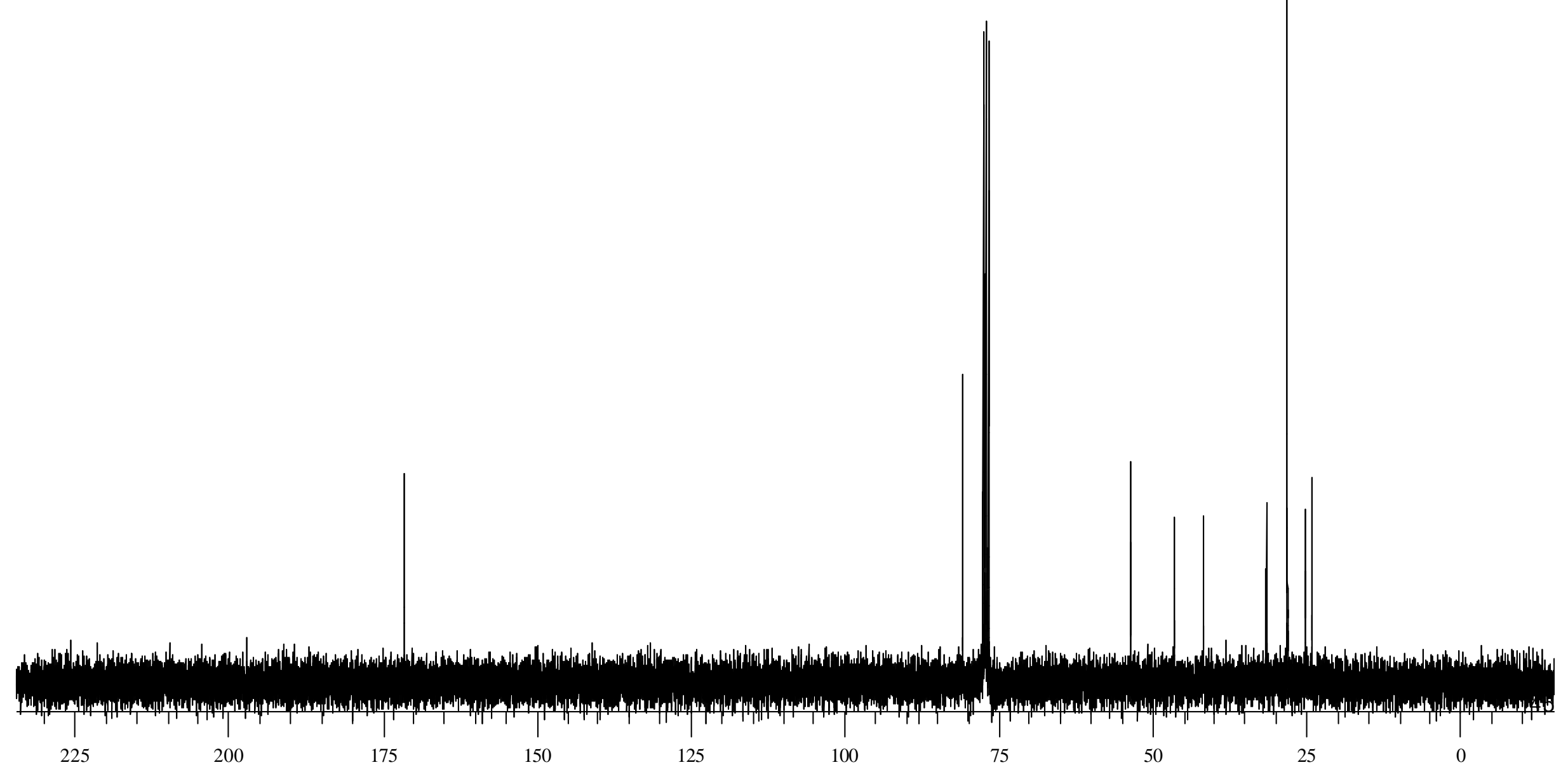


$\sum_{24}^{N-O} \cdot \cdots \mathrm{CO}_{2} t-\mathrm{Bu}$

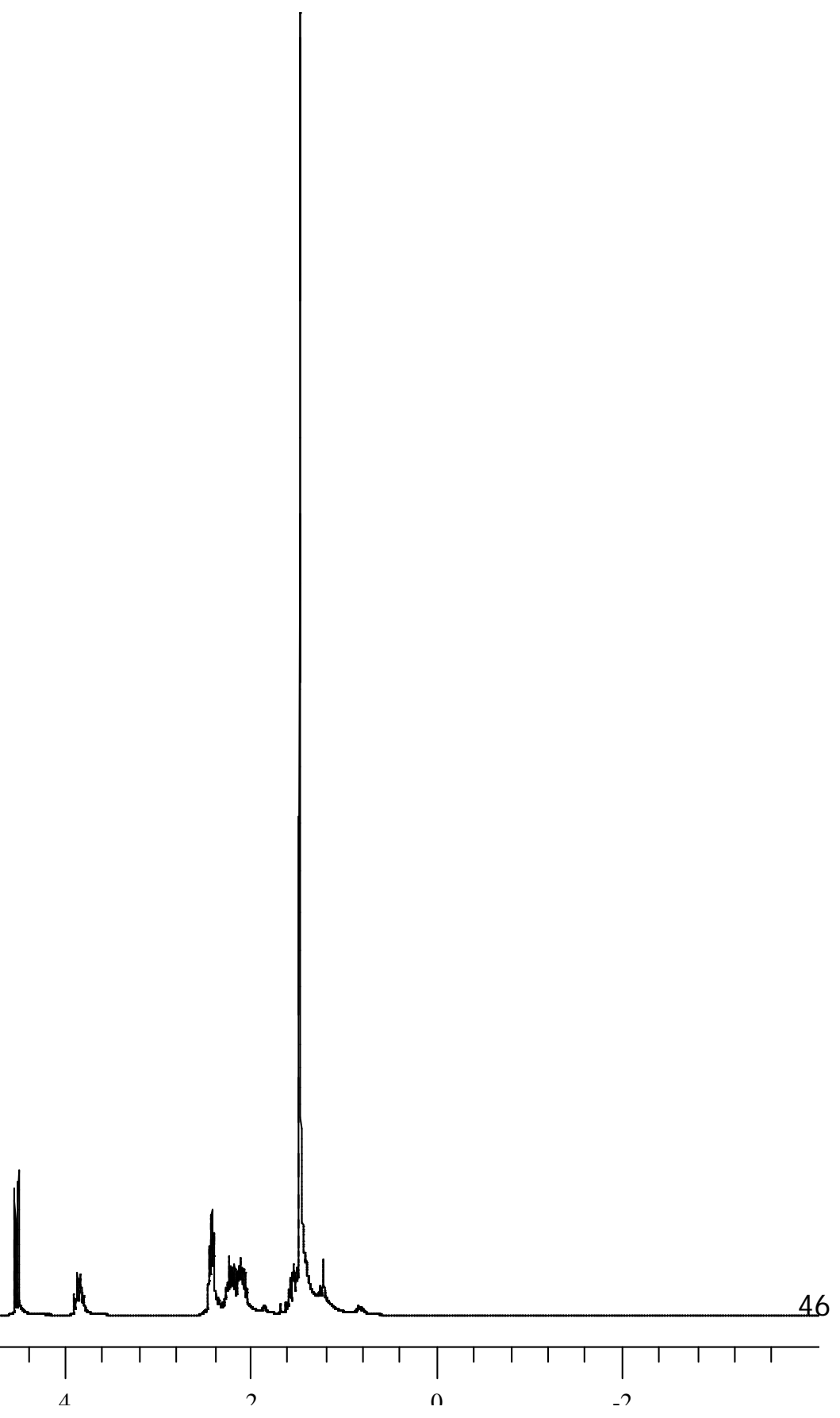


<smiles>CCCOC(=O)C1ON=C2CCCC21</smiles>

24

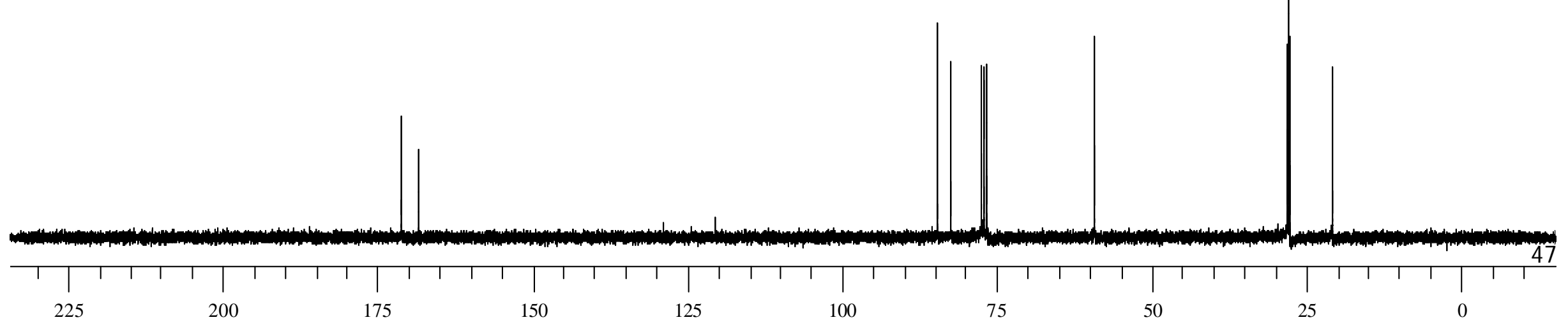


$\overbrace{25}^{\mathrm{N}-\mathrm{O}} \cdot \mathrm{CO}_{2} \mathrm{Me}$

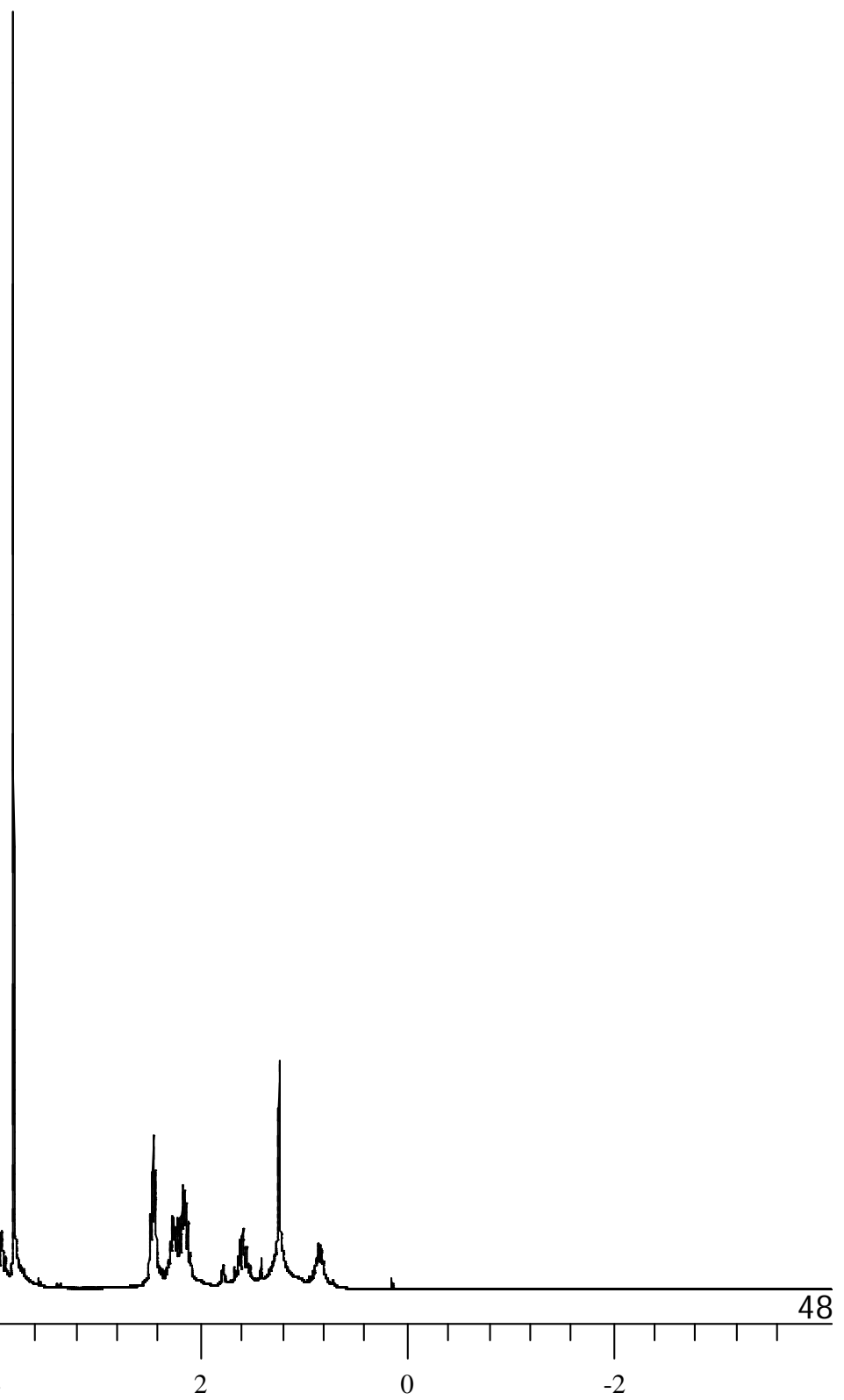



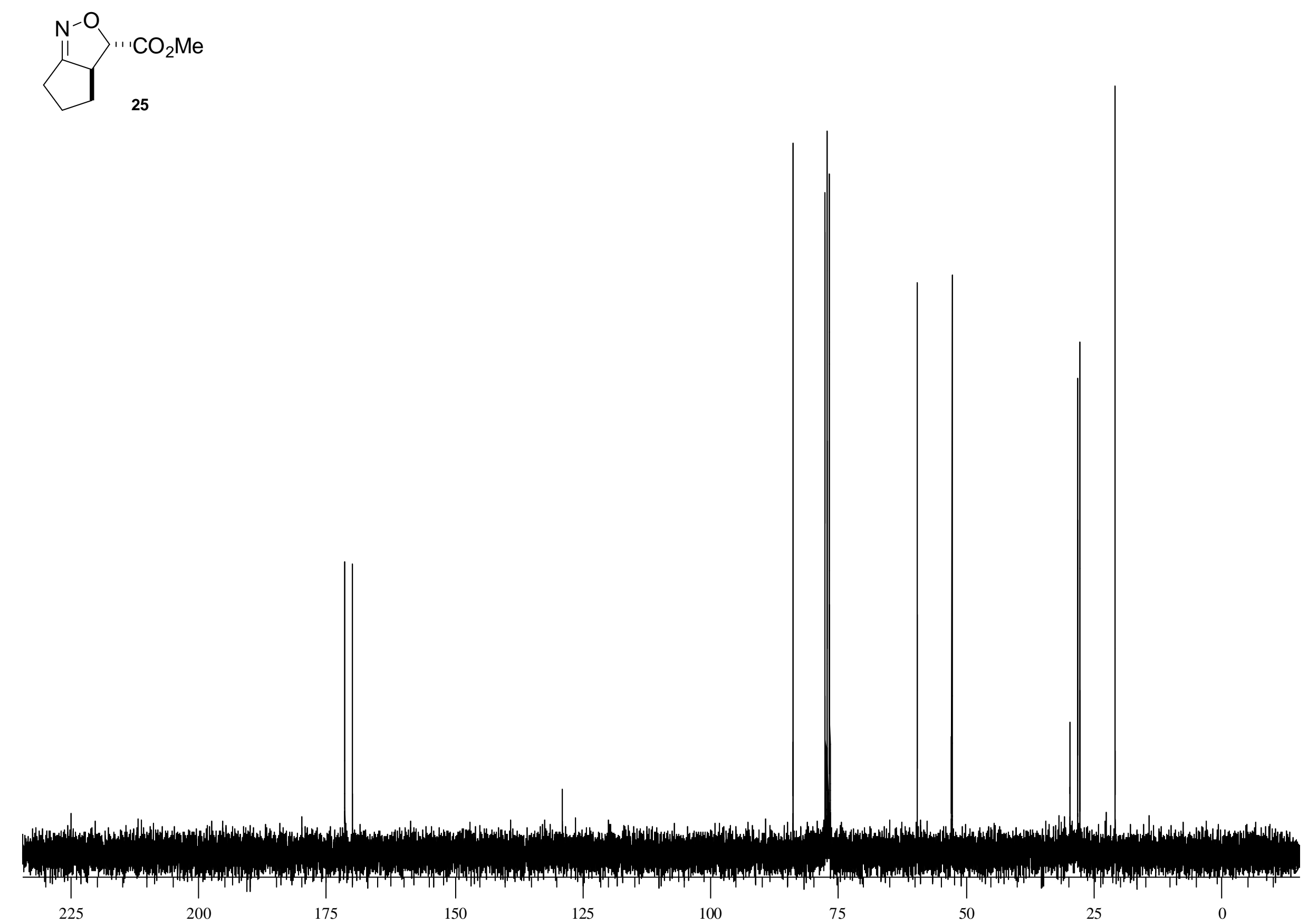


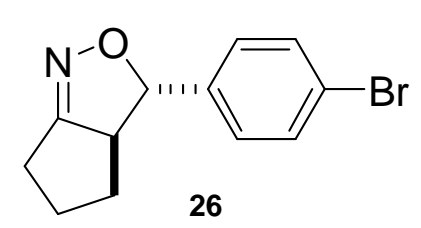

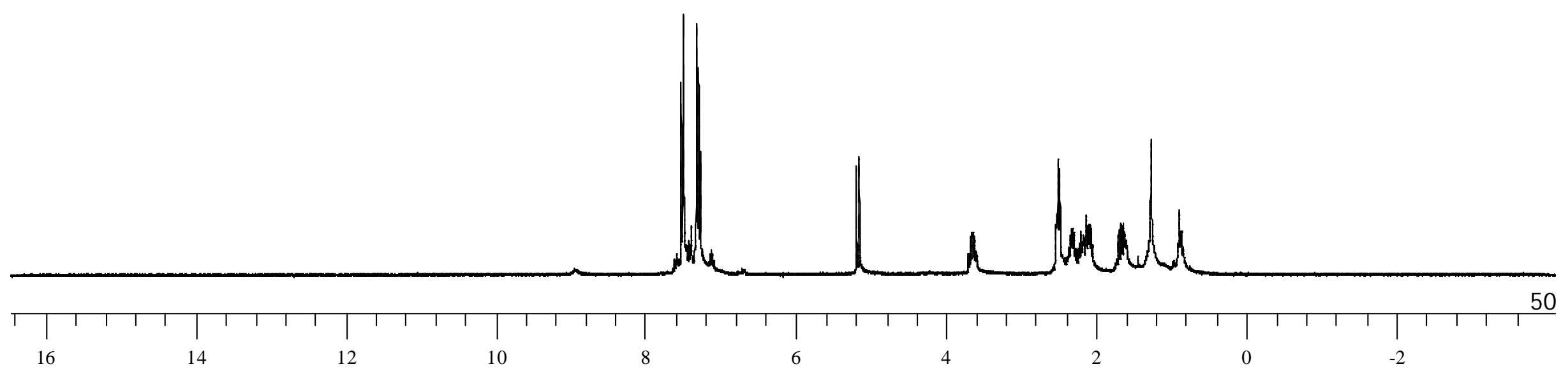


